\title{
Functional diversity and life history traits of arbuscular mycorrhizal fungi in disturbed soils
}

\author{
Kelly Marie Fleming \\ West Virginia University
}

Follow this and additional works at: https://researchrepository.wvu.edu/etd

\section{Recommended Citation}

Fleming, Kelly Marie, "Functional diversity and life history traits of arbuscular mycorrhizal fungi in disturbed soils" (1999). Graduate Theses, Dissertations, and Problem Reports. 1026.

https://researchrepository.wvu.edu/etd/1026

This Thesis is protected by copyright and/or related rights. It has been brought to you by the The Research Repository @ WVU with permission from the rights-holder(s). You are free to use this Thesis in any way that is permitted by the copyright and related rights legislation that applies to your use. For other uses you must obtain permission from the rights-holder(s) directly, unless additional rights are indicated by a Creative Commons license in the record and/ or on the work itself. This Thesis has been accepted for inclusion in WVU Graduate Theses, Dissertations, and Problem Reports collection by an authorized administrator of The Research Repository @ WVU. For more information, please contact researchrepository@mail.wvu.edu. 


\title{
FUNCTIONAL DIVERSITY AND LIFE HISTORY TRAITS
}

\section{OF ARBUSCULAR MYCORRHIZAL FUNGI IN DISTURBED SOILS}

\author{
Kelly M. Fleming \\ Thesis submitted to the \\ College of Agriculture, Forestry, and Consumer Sciences \\ of West Virginia University \\ in partial fulfillment of the requirements \\ for the degree of \\ Master of Science \\ in \\ Plant and Soil Sciences \\ with an emphasis in \\ Environmental Microbiology
Joseph Morton, Ph.D., Chair
Daniel Panaccione, Ph.D. Rajeev Arora, Ph.D. \\ 1999 \\ Morgantown, West Viginia
}

Keywords: Mycorrhizae, Disturbed Soils, Community, Ecology 


\title{
FUNCTIONAL DIVERSITY AND LIFE HISTORY TRAITS
}

\section{OF ARBUSCULAR MYCORRHIZAL FUNGI IN DISTURBED SOILS}

\author{
Kelly M. Fleming
}

\begin{abstract}
(ABSTRACT)
Relative effectiveness of ten species of arbuscular mycorrhizal fungi native to a revegetated coal strip mine site was tested on red clover against a non-mycorrhizal control and against inocula of two commercial isolates. Most (70\%) of the isolated species in a native fungal community were as effective at promoting growth as commercial isolates. The net benefit of native colonizing fungi likely was positive, since the majority of the fungi colonizing two-year-old apple and grape in the field also were effective symbionts. The relationship between colonization and sporulation was compared among one Acaulospora, two Glomus, one Gigaspora, and one Scutellospora species on red clover. Threshold levels of colonization at which sporulation was initiated ranged from $10 \%$ (G. etunicatum) to a maximum of $30 \%$ (Gi. gigantea, S. heterogama).
\end{abstract}




\section{DEDICATION}

A colleague of my husband once told him that when he wrote a scientific article, he should imagine that he were sitting on a porch swing with his grandmother, telling her about his research.

I kept that advice in mind as I wrote this thesis.

This is dedicated to my grandmother, Helen O'Dell. 


\section{ACKNOWLEDGEMENTS}

I would like those who worked in the INVAM laboratory during both the experimental and writing phases of this thesis. A special thanks goes to my advisor, Dr. Joseph Morton, for his guidance and patience. Dr. Steve Bentivenga was invaluable with his suggestions and for help with data interpretation and presentation. I am grateful to Bill Wheeler, Elizabeth Thomas, Katie Dailer, and Stacey Waugh for technical assistance. My fellow graduate students, Sidney Stürmer, Kris Nichols, Jill Ferrell, and Bill Shick were very supportive and a pleasure with whom to work.

Dr. Daniel Panaccione and Dr. Rageev Arora offered very helpful comments on this thesis. I would also like to thank Dr. Alan Sexstone and Dr. Gary Bissonnette for their encouragement.

Thanks to Donna Ford-Werntz for assistance in field plant identification, and to Dr. Edwin Townsend, Dr. William Thayne, and Dr. James Kotcon for statistical assistance. Thanks to Carole Cheuvront for fashioning the nylon mesh sleeves used in Chapter 2.

I would like to offer a special thanks to the Department of Environmental Microbiology and Plant Pathology at WVU for a great working environment. Also, thanks to Samantha Smith for her support and friendship.

Thanks to my husband, Jim Fleming, and my parents, John and Rita Heldreth, for their encouragement and support.

Lastly, thanks to the Mingo County Redevelopment Authority for financial support. Also, a special thanks to the inmates from the Mingo County jail who assisted in the field work for this study. 


\section{TABLE OF CONTENTS}

ABSTRACT. Page

Chapter 1 - Functional diversity of a community of arbuscular mycorrhizal fungal species native to a revegetated coal strip mine site ................................. 10

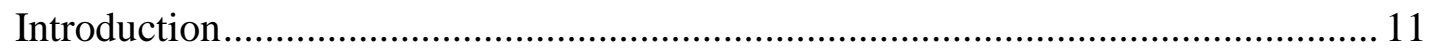



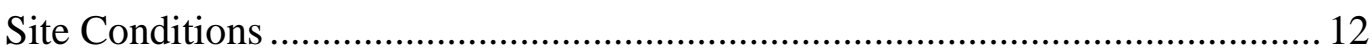

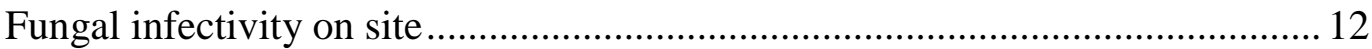

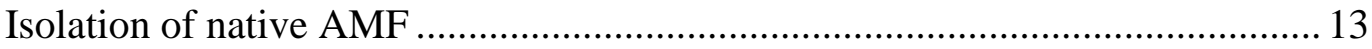

Relative effectiveness of native AMF ........................................................... 13

Composition of the AMF community in field-grown apple and grape................ 14

Aggressiveness and host preference of a community of selected native AMF... 15

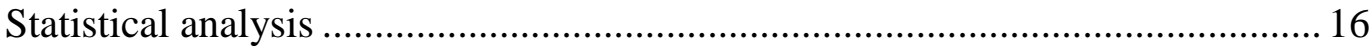

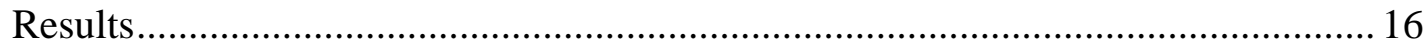

Composition of native AMF community ........................................................ 16

Relative effectiveness of native AMF ....................................................... 17

Composition of AMF community in field-grown apple and grape...................... 17

Aggressiveness and host preference of a community of selected native AMF... 18

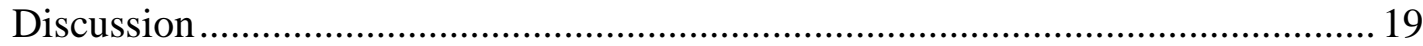

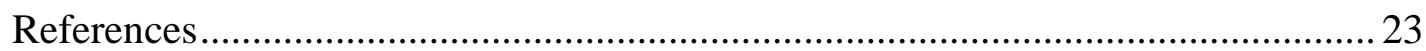

Chapter 2 - Threshold levels of mycorrhizal colonization are needed for sporulation by fungal species in Glomales....................................................... 36

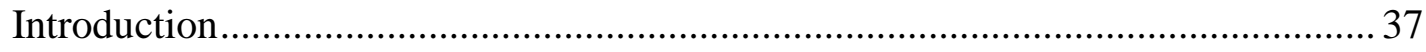

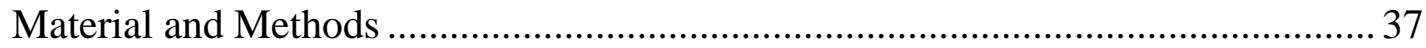

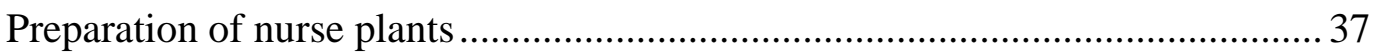

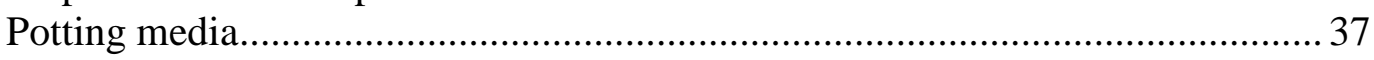

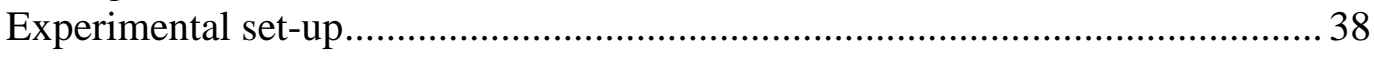




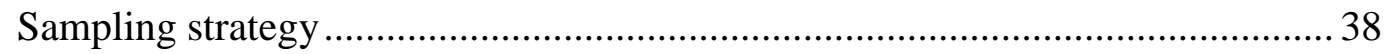

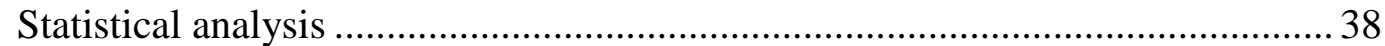

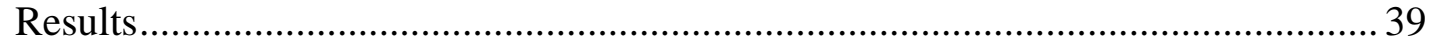

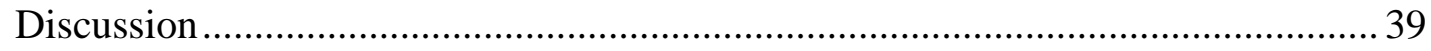

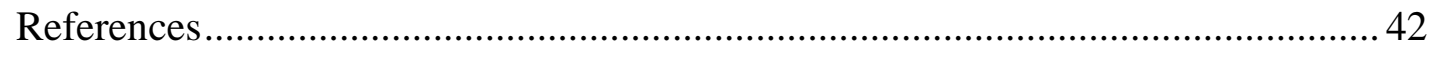

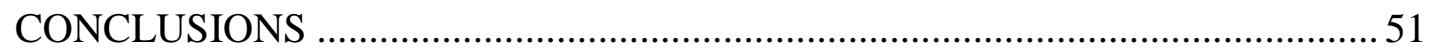

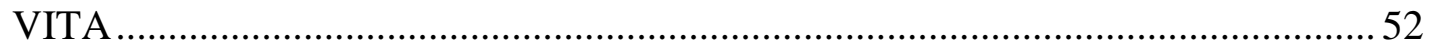

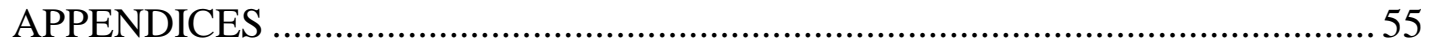




\section{LIST OF TABLES}

Chapter 1 Page

$1 \quad$ Plant species composition in plots, Mingo County, West Virginia......................29

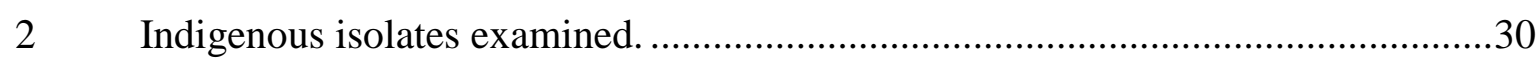

3 Responses (mean $\pm \mathrm{SE}$ ) of 7-week-old red clover plants to colonization by native isolates, a negative control, and positive controls (commercial isolates UT316 and BR147B alone or combined) ............................................... 31

\section{Chapter 2}

1 Summary of predicted threshold levels of colonization based on

Gompertz equations. 


\section{LIST OF FIGURES}

\section{Chapter 1}

1 Responses of 7-week-old red clover plants to colonization by indigenous isolates from Mingo County plots and commercial isolates

2 Occurrence of AMF species detected by sporulation in trap cultures of apple and grape roots at several sampling dates

3 Dominant fungi sporulating in trap pot cultures of apple and grape roots collected on two sampling dates

4 Sporulation by AMF isolates in a mixed inoculum grown on three different host plants at two dilutions

\section{Chapter 2}

1 Experimental set-up

2 Relationship between percentage mycorrhizal colonization and sporulation by Acaulospora morrowiae BR983A in red clover grown at two $\mathrm{P}$ concentrations

3 Relationship between percentage mycorrhizal colonization and sporulation by Glomus etunicatum WV977 in red clover grown at two $\mathrm{P}$ concentrations...

$4 \quad$ Relationship between percentage mycorrhizal colonization and sporulation by Glomus intraradices UT187 in red clover grown at two $\mathrm{P}$ concentrations

5 Relationship between percentage mycorrhizal colonization and sporulation by Gigaspora gigantea MN922A in red clover grown at two $\mathrm{P}$ concentrations

6 Relationship between percentage mycorrhizal colonization and sporulation by Scutellospora heterogama WV858B in red clover grown at two $\mathrm{P}$ concentrations 


\section{INTRODUCTION}

Arbuscular endomycorrhizae are symbiotic mutualistic associations between most terrestrial plant species and soil fungi in the order Glomales (Zygomycetes) (Trappe, 1987). Mycorrhiza formation is the rule rather than the exception among plants (Smith and Read, 1997). The plant supplies the fungus with carbon and the fungus benefits the plant by absorbing and translocating immobile nutrients in soil, especially phosphorus (P). Arbuscular mycorrhizal fungi (AMF) are the most primitive of present-day mycorrhizae. Geologic history suggests that land could be colonized only due to the symbiosis between a semi-aquatic alga and an aquatic oomycete, and that plants and mycorrhizal fungi have co-evolved over a period of 400 million years (Pirozynski and Dalpé, 1989). Non-mycorrhizal plants most likely have evolved from mycorrhizal ancestors (Trappe, 1987). However, the number of non-mycorrhizal plant families is small, and consists mostly of Amaranthaceae, Brassicaceae, Caryophyllaceae, Chenopodiaceae, Commelinaceae, Lecythidaceae, Portulacaceae, Proteaceae, Restionaceae, Sapotaceae, and Zygophyllaceae (Sieverding, 1991).

AMF are distributed worldwide, and they colonize a diversity of habitats. They are commonly associated with herbaceous and woody plants on mineral soils (Miller and Jastrow, 1994), and they are well-adapted to eutrophic soil (Harley, 1989). Arbuscular mycorrhizae are the predominant fungal symbiosis in arid and semiarid biomes, and AMF are plentiful in soils with low organic matter, such as in moist tropical forests (Allen et al., 1995). The global distribution of both ancestral and more recently derived species, and the representation of all genera in most plant root systems (Morton et al., 1995), suggests that the distribution of AMF species probably has been greatly affected by dispersal over geologic time. Ecological processes still are very important, but at the local level.

\section{Benefits to plants in agricultural and natural ecosystems}

In both agricultural and natural communities, AMF may confer considerable benefits to the host plant. If the plant has large reserves of $\mathrm{P}$, it may not be as dependent on mycorrhizae until the reserves are depleted. For instance, Habte and Byappanahalli (1994) found that large cuttings of mycorrhizal cassava were not as dependent as smaller cuttings.

Mycorrhizal fungi also may improve the uptake of other nutrients (Abbott and Robson, 1984; Harley, 1989). However, some researchers have observed decreases in micronutrient concentration in inoculated plants, due to a dilution effect from dry matter production (e.g., Mohammad et al., 1995). However, high $\mathrm{P}$ additions may be used to obtain non-mycorrhizal and mycorrhizal plants of similar size; using this technique, Menge et al. (1978) found higher concentrations of $\mathrm{Zn}, \mathrm{Cu}$, and $\mathrm{Mn}$ for mycorrhizal plants, suggesting that the fungus directly aids in their adsorption (Menge et al., 1978a).

\section{Fungal community dynamics}

Individual species of AMF usually are not found alone in the field (Hayman, 1982; Morton et al., 1995). AMF form complex communities in host roots that can vary with local environmental conditions and perhaps plant community structure (Allen et al., 1995 and 
references within). The structure of these populations is determined by factors such as microheterogeneity of the soil, the age and activity of the roots, and the ability of the different fungi to colonize roots under the given conditions (Garbaye, 1991). In addition, the hyphae from fungi colonizing different hosts can be interconnected in the soil, forming a 'social complex of organisms' (Friese and Allen, 1991; Newman et al., 1994; Smith and Read, 1997). The importance of hyphal links includes the passage of nutrients between plants, and from dying to living roots (reviewed by Miller and Jastrow, 1994).

Competition between fungi may occur in an AMF community. Pearson et al. (1993) found that percentage colonization of clover by Glomus sp. decreased when S. calospora was present, even if the two fungi were separated in a split-root experiment. The authors also reported a decrease in arbuscules and vesicles for the Glomus sp., suggesting that a greater capacity of $S$. calospora to obtain carbohydrates was a determining factor in the competition, decreasing colonization by Glomus sp. This hypothesis is supported by the observation that a decline in percent colonization of clover by $S$. calospora at the 6 week harvest (increasing root carbohydrate levels) was associated with an increase in colonization by Glomus sp. on the other side of the split-root, as well as an increase in arbuscules and vesicles of Glomus sp. (Pearson et al., 1993).

Competition between AMF may be influenced by the infectivity and aggressiveness of isolates. Infectivity (or inoculum potential) is a measure of the number of total infectious propagules around the root as defined by a particular set of assay conditions. Fungi with higher inoculum potentials may outcompete those with lower potentials due to competition for space within the root (Abbott and Robson, 1981a). Aggressiveness, on the other hand, is measured by the rate of mycorrhizal development (percentage colonization) by a particular isolate. Plant species also may affect the AMF populations, because the fungus cannot survive without the host (Janos, 1980). Low fungus content can be expected where non-mycorrhizal plants are growing, in fertile areas with facultative mycotrophs, or in the tropics, where there are few spores (Janos, 1980).

Both infectivity and aggressiveness must be considered when comparing effectiveness among fungal isolates, because growth benefits are influenced by timing of mycorrhizal establishment during an experiment of finite duration. For example, Abbott and Robson (1981a) found a correlation between colonization by inoculant fungi and growth benefit (measured by fresh weight of subterranean clover shoots). Conversely, no such correlation was evident in similar cultures prepared with native fungi. The former correlation was attributed to rapid, early colonization by inoculant fungi with a higher inoculum potential than that of the native species. Morin et al. (1994) were unable to correlate effectivness with percentage colonization in apple rootstocks. This study indicated that other factors, such as amount of external mycelium, contributed significantly to effective growth responses. Therefore, any study of effectiveness must involve equalization of inoculum potential so that all fungal isolates initiate colonization with similar numbers of propagules. 


\section{Plant community dynamics}

Agricultural and natural communities differ in their population ecology. In agroecosystems, fungi are exposed to single crops, and the mycorrhizae may be affected by crop rotation and types of cropping systems. For example, Johnson et al. (1991a) found E. infrequens spores in plots with a soybean history, but not in plots with a corn history, though the ShannonWiener diversity index was higher for the latter. Johnson et al. (1991b) found that in a field to forest chronosequence, communities of AMF changed in species composition. Seven of the twenty-five observed species, such as $S$. erythropa, were early successional, and five species, such as A. elegans, were late successional. The Shannon-Wiener diversity index indicated that diversity increased with successional time due to increasing evenness of the community, although the number of species did not increase.

In natural ecosystems, AMF are exposed to a heterogenous plant community, with plants in competition with one another. In fact, plants and mycorrhizal fungi may interact to influence plant species richness and plant community succession (Allen, 1991; Gange et al., 1990; Newman and Reddell, 1988; Janos, 1980). The occurrence of obligate mycotrophs is particularly dependent on AMF (Allen et al., 1995). Non-mycorrhizal plants may be important in early stages of succession, especially in arid habitats where infectivity of native fungal propagules often is low. In later stages of succession, facultatively mycorrhizal plants may be more heavily colonized, and obligately mycorrhizal plants may be most important in mature stands (Janos, 1980).

Mycorrhizae influence plant diversity, stability, and competition at the community level, and are important in nutrient retention and cycling at the ecosystem level (Miller and Jastrow, 1994). AMF may increase the establishment and biomass of subordinate plant species (Grime et al., 1987) and may enhance seedling establishment of perrenial forbs (Gange et al., 1993). They may release compounds such as oxalate and $\mathrm{CO}_{2}$, and by influencing soil $\mathrm{pH}, \mathrm{AMF}$ can influence nutrient cycling in the rhizosphere, thus affecting the plant community (reviewed by Miller and Jastrow, 1994). Using experimental microcosms, van der Heijden et al. (1998) showed that different plant species respond differentially to different AMF species, and that at low AMF diversity, an alteration in the composition and numbers of AMF taxa can lead to large fluctuations in the structure and composition of the plant community. However, Allen et al. (1995) argue that the influence of AMF on plant diversity is confined to small areas due to the small networks of hyphae and lack of host specificity.

\section{Disturbance}

Disturbance, with its changes in the physical, chemical, and/or biological environment, may affect the abundance and distribution of AMF, either directly or indirectly through effects on plant growth (Abbott and Robson, 1991). Although AMF populations may be able to adjust to minor disturbances, extreme or rapid disturbance may greatly decrease colonization. Following land disturbance in western Colorado, Moorman and Reeves (1979) observed a decrease in colonization of $G$. fasciculatus on corn from $77 \%$ to $2 \%$. Initially following disturbance, there may be an increase in diversity due to input from surrounding soil, or diversity may decrease due 
to factors such as soil removal or changes in conditions to those that the indigenous fungi are not adapted to, or in which they cannot compete with other fungi (Abbott and Gazey, 1994). However with increasing disturbance, decreasing AMF diversity is expected in the long term (Abbott and Robson, 1991; Abbott and Gazey, 1994).

Reduced inoculum levels caused by disturbance may curtail the rate of establishment of plant species (Warner et al., 1987). Moreover, endemic plant species may not be adapted to the new conditions (Linderman, 1988).

\section{Introduced fungi}

Many researchers have suggested inoculating disturbed sites with mycorrhizal fungi to mitigate the damage (e.g., Daft and Hacskaylo, 1976; Mohammad et al., 1995). When disturbed areas are dominated by non-mycorrhizal and facultatively mycotrophic plant species, the introduction of mycorrhizal fungi will allow obligate mycotrophs to become established. However, if AMF are not introduced, successional stages will be comprised of non-mycorrhizal species (Janos, 1980).

Culture collections are a good source of inoculum for introduction, because a variety of species are readily available. One such collection is INVAM, the International Collection of Arbuscular and Vesicular-Arbuscular Mycorrhizal Fungi, housed at West Virginia University (Morton et al., 1993). Once fungal isolates are obtained in culture, inoculum may be prepared for distribution. The quantity of inoculum is important because any differences in competitiveness may simply be a function of inoculum potential (Pearson et al., 1993; Moorman and Reeves, 1979). Plants may be inoculated prior to planting, or inoculum may be added directly to the site.

Inoculum should be effective, concentrated, pathogen-free, infective under conditions in which it is introduced, and should have a long shelf life (Jarstfer and Sylvia, 1993). Placement of inoculum may affect the rate of colonization (Jarstfer and Sylvia, 1993). The fungi must infect roots rapidly (Abbott and Robson, 1981b), and must be able to compete with native populations (Menge, 1983). The species of mycorrhizal fungi that is introduced is also very important (Schubert et al., 1988; Moorman and Reeves, 1979). It may be advantageous to inoculate with fungi that are native to the site, because they may be more adapted to the plants or soil type (Schubert et al., 1986; Graham et al., 1982).

\section{Management of native versus introduced AMF}

Many researchers have contemplated the management of native versus introduced fungi. Garbaye (1991) suggests that inoculating with species that protect the plant from pathogens would be highly advantageous, or that managing the mycorrhizosphere's microflora, or introducing helper organisms along with AMF inoculum also may be useful. Johnson (1993) also suggests that agricultural practices that select for beneficial AMF should be used. Daft (1992) proposes manipulating the indigenous AMF, for example by adding urea, straw, and/or rock phosphate. It is important to realize that processes that enhance plant production will not necessarily increase "agrosystem stability;" for example $\mathrm{N}$ applied as $\mathrm{NH}_{4}-\mathrm{N}$ may increase plant 
growth, but the growth medium could become acidified (Bethlenfalvay and Schüepp, 1994). Obviously, due to the importance of competitive interactions between fungi, more field research is needed (Abbott and Gazey, 1994). 


\section{REFERENCES}

Abbott, L. K., and C. Gazey. 1994. An ecological view of the formation of VA mycorrhizas. Plant and Soil 159:69-78.

Abbott, L. K., and A. D. Robson. 1981a. Infectivity and effectiveness of five endomycorrhizal fungi: Competition with indigenous fungi in field soils. Australian Journal of Agricultural Research 32:621-630.

Abbott, L. K., and A. D. Robson. 1981b. Infectivity and effectiveness of vesicular arbuscular mycorrhizal fungi: effect of inoculum type. Australian Journal of Agricultural Research 28:639-645.

Abbott, L. K., and A. D. Robson. 1984. The effect of VA mycorrhizae on plant growth. In: VA Mycorrhiza, C.Ll. Powell and D.J. Bagyaraj, eds. pp. 113-130. CRC Press, Boca Raton, Florida, USA.

Abbott, L. K., and A. D. Robson. 1991. Factors influencing the occurrence of vesiculararbuscular mycorrhizas. Agriculture, Ecosystems and Environment 35:121-150.

Allen, M. F. 1991. The Ecology of Mycorrhziae. Cambridge University Press, Cambridge.

Allen, E. B., M. F. Allen, D. J. Helm, J. M. Trappe, R. Molina, and E. Rincon. 1995. Patterns and regulation of mycorrhizal plant and fungal diversity. In: The significance and regulation of soil biodiversity, H. P. Collins, G. P. Robertson, and M. J. Klug, eds. pp. 47-62. Kluwer Academic Publishers, Netherlands.

Bethlenfalvay, G. J., and H. Schüepp. 1994. Arbuscular mycorrhizas and agrosystem stability. In: Impact of arbuscular mycorrhizas on sustainable agriculture and natural ecosystems, S. Gianinazzi and H. Schüepp, eds. pp. 117-127. Birkhäuser Verlag Basel, Switzerland.

Cooke, J. C., J. N. Gemma, and R. E. Koske. 1987. Observations of nuclei in vesiculararbuscular mycorrhizal fungi. Mycologia 79:331-333.

Daft, M. J. 1992. Use of VA mycorrhizas in agriculture: problems and prospects. In: Mycorrhizas in ecosystems, D. J. Read, D. H. Lewis, A. H. Fitter, and I. J. $\quad$ Alexander, eds. pp. 198-201. C.A.B. International, Wallingford, Oxon, UK.

Daft, M. J., and E. Hacskaylo. 1976. Arbuscular mycorrhizae in the anthracite and bituminous coal wastes of Pennsylvania. Journal of Applied Ecology 13:523-531.

Friese, C. F., and M. F. Allen. 1991. The spread of VA mycorrhizal fungal hyphae in the soil: inoculum types and external hyphal architecture. Mycologia 83:409-418. 
Gange, A. C., V. K. Brown, and L. M. Farmer. 1990. A test of mycorrhizal benefit in an early successional plant community. New Phytologist 115:85-91.

Gange, A. C., V. K. Brown, and G. S. Sinclair. 1993. Vesicular-arbuscular mycorrhizal fungi: a determinant of plant community structure in early succession. Functional Ecology 7:616622.

Garbaye, J. 1991. Biological interactions in the mycorrhizosphere. Experientia 47:370-375.

Graham, J. H., R. G. Linderman, and J. A. Menge. 1982. Development of external hyphae by different isolates of mycorrhizal Glomus spp. in relation to root colonization and growth of Troyer citrange. New Phytologist 91:183-189.

Grime, J. P., J. M. L. Mackey, S. H. Hillier, and D. J. Read. 1987. Floristic diversity in a model system using experimental microcosms. Nature 328:420-422.

Habte, M., and M. N. Byappanahalli. 1994. Dependency of cassava (Manihot esculanta Crantz) on vesicular-arbuscular mycorrhizal fungi. Mycorrhiza 4:241-245.

Harley, J. L. 1989. The fourth benefactors' lecture: The significance of mycorrhiza. Mycological Research 92:129-139.

Hayman, D. S. 1982. Influence of soils and fertility on activity and survival of vesiculararbuscular mycorrhizal fungi. Phytopathology 72:1119-1125.

Janos, D. P. 1980. Mycorrhizae influence tropical succession. Biotropica 12:56-64.

Jarstfer, A. G. and D. M. Sylvia. 1993. Inoculum production and inoculation strategies for vesicular-arbuscular mycorrhial fungi. In: Soil Microbial Ecology, B. F. Metting, ed. pp. 349-377. Marcel Decker, Inc. New York.

Johnson, N. C. 1993. Can fertilization of soil select less mutualistic mycorrhizae? Ecological Applications 3:749-757.

Johnson, N. C., F. L. Pfleger, R. K. Crookston, S. R. Simmons, and P. J. Copeland. 1991a. Vesicular-arbuscular mycorrhizas respond to corn and soybean cropping history. New Phytologist 117:657--663.

Johnson, N. C., D. R. Zak, D. Tilman, and F. L. Pfleger. 1991b. Dynamics of vesiculararbuscular mycorrhizae during old field succession. Oecologia 86:349-358.

Linderman, R. G. 1988. VA (vesicular-arbuscular) mycorrhizal symbiosis. Animal and Plant Sciences 1:183-188. 
Menge, J. A. 1983. Utilization of vesicular-arbuscular mycorrhizal fungi in agriculture. Canadian Journal of Botany 61:1015-1024.

Menge, J. A.,C. K. Labanauskas, E. L. V. Johnson, and R. G. Platt. 1978. Partial substitution of mycorrhizal fungi for phosphorus fertilization in the greenhouse culture of citrus. Soil Science Socity of America Journal 42:926-930.

Miller, R. M., and J. D. Jastrow. 1994. Vesicular-arbuscular mycorrhizae and biogeochemical cycling. In: Mycorrhizae and plant health, F. L. Pfleger and R. G. Linderman, eds. pp. 189-212. APS Press, St. Paul, Minnesota.

Mohammad, M. J., W. L. Pan, and A. C. Kennedy. 1995. Wheat responses to vesiculararbuscular mycorrhizal fungal inoculation of soils from eroded toposequence. Soil Science Society of America Journal 59:1086-1090.

Moorman, T., and F. B. Reeves. 1979. The role of endomycorrhizae in revegetation practices in the semi-arid west. II. A bioassay to determine the effect of land disturbance on endomycorrhizal populations. American Journal of Botany 66:14-18.

Morin, F., J. A. Fortin, C. Hamel, R. L. Granger, and D. L. Smith. Apple rootstock response to vesicular-arbuscular mycorrhizal fungi in a high phosphorus soil. Journal of the American Society of Horticultural Science 119:578-583.

Morton, J. B., S. P. Bentivenga, and J. D. Bever. 1995. Discovery, measurement, and interpretation of diversity in arbuscular endomycorrhizal fungi (Glomales, Zygomycetes). Canadian Journal of Botany 73:S25-S32.

Morton, J. B., S. P. Bentivenga, and W. W. Wheeler. 1993. Germ plasm in the international collection or arbuscular and vesicular-arbuscular mycorrhizal fungi (INVAM) and procedures for culture development, documentation and storage. Mycotaxon 48:491-528.

Newman, E. I., C. L. N. Devoy, N. J. Easen, and K. J. Fowles. 1994. Plant species that can be linked by VA mycorrhizal fungi. New Phytologist 126:691-693.

Newman, E. I., and P. Reddell. 1988. Relationship between mycorrhizal infection and diversity in vegetation: evidence from the Great Smoky Mountains. Functional Ecology 2:259-262.

Pearson, J. N., L. K. Abbott, and D. A. Jasper. 1993. Mediation of competition between two colonizing VA mycorrhizal fungi by the host plant. New Phytologist 123:93-98.

Pirozynski, K. A., and Y. Dalpé. 1989. Geological history of the Glomaceae with particular reference to mycorrhizal symbiosis. Symbiosis 7:1-36. 
Schubert, A., S. Cammarata, and O. Ariusso. 1986. Inoculation of grapevine plants with VA mycorrhizal fungi in unsterile soil. Proceedings of the 3rd International Symposium on Grapevine Physiology, O.I.V., Paris, 303-307.

Schubert, A., S. Cammarata, and I. Eynard. 1988. Growth and root colonization of grapevines inoculated with different mycorrhizal endophytes. HortScience 23:302-303.

Sieverding, E. 1991. Vesicular-arbuscular mycorrhiza management in tropical agrosystems. Technical Cooperation, Federal Republic of Germany, Eschborn.

Smith, S.E. \& Read, D.J. 1997. Mycorrhizal Symbiosis. San Diego:Academic Press.

Trappe, J. M. 1987. Phylogenetic and ecologic aspects of mycotrophy in the angiosperms from an evolutionary standpoint. In: Ecophysiology of VA mycorrhizal plants, G.R. Safir, ed. pp. 2-25. CRC Press. Boca Rotan, Florida.

van der Heijden, M. G. A., J. N. Klironomos, M. Ursic, P. Moutoglis, R. Streitwolf-Engel, T. Boller, A. Wiemken, and I. R. Sanders. 1998. Mycorrhizal fungal diversity determines plant biodiversity, ecosystem variability and productivity. Nature 396:69-72.

Warner, N. J., M. F. Allen, and J. A. MacMahon. 1987. Dispersal agents of vesiculararbuscular mycorrhizal fungi in a disturbed arid ecosystem. Mycologia 79:721-730. 


\section{CHAPTER ONE}

FUNCTIONAL DIVERSITY OF A COMMUNITY OF ARBUSCULAR

MYCORRHIZAL FUNGAL SPECIES NATIVE TO A REVEGETATED

COAL STRIP MINE SITE 


\section{INTRODUCTION}

Arbuscular mycorrhizal fungi (AMF) in Glomales, Zygomycetes (Morton and Benny, 1990) are mutualists of a vast range (ca. 80\%) of terrestrial plant species (Trappe, 1987). Mycorrhizal plants benefit from increased uptake of immobile nutrients in the soil, especially phosphorus, in exchange for carbon provided to the fungus (Smith and Read, 1997). AMF communities are obligate biotrophs and therefore must grow and reproduce solely in plant roots (Brundrett, 1991). The persistence and widespread distribution of the arbuscular mycorrhizal symbiosis throughout the 400 million years of plant evolution and radiation (Morton, 1990; Pirozynski and Dalpe, 1989; Simon et al., 1992) suggest it has had either a neutral or a net positive benefit to plant communities.

AMF communities in plant roots are taxonomically heterogeneous, with a multitude of trap cultures indicating a range of 2-9 species generally present at any given time (Morton, 1999). Using an eclectic mix of culturing methods, Bever et al. (1996) were able to isolate as many as 23 AMF species from a local old field plant community. Despite an increasing awareness of such taxonomic complexity, little has been done to ascertain the magnitude of functional diversity within members of a fungal community.

Fungal symbionts can benefit plants in many ways at the scale of the community. Fecundity (Bryla and Koide, 1990), pollen production (Lau et al., 1995), seedling vigor (Stanley et al., 1993), putative resistance to root pathogens (Newsham et al., 1994), and size/behavior of below-ground absorptive surfaces (Campbell et al., 1991) can be increased. Phenology and P relationships (Merryweather and Fitter, 1995a), nutrient source-sink relationships (Eissenstat et. al., 1993; Merryweather and Fitter, 1995b), root behavior and architecture (Hetrick et al., 1992), or plant community successional changes as a function of each plant genotype's mycorrhizal dependency (Titus and del Moral, 1998) can be altered. Benefit to individual plants generally is measured by enhancements to growth, nutrient uptake, or yield of the experimental plant species (Ollivier et al., 1983; Powell et al., 1982; Ravnskov and Jakobsen, 1995; Stanley et al., 1993; Wilson, 1988). Generally, any or all of these plant responses could be used to measure "effectiveness" of fungal genotypes participating in the mycorrhizal symbiosis.

Competitiveness and persistence of fungal genotypes also are important determinants in the long-term composition of a fungal community interacting with plants, and this generally is measured by the genotype's infectiveness or aggressiveness in colonizing roots (Afek et al., 1990; Boerner et al., 1996; Wilson, 1984). Host and fungal physiology, as well as external variables, are interdependent, since the fungal symbiont is not culturable and growth is not measured independent of the plant. For example, plant community structure and soil factors impact measurably on AMF species richness (del Val et al., 1999; Hendrix et al., 1995; Johnson et al., 1992). The complexity of these interactions at the community level cannot be sorted out until the relative contribution, either positive or negative, of the component fungi to the symbiosis is ascertained.

In this study, pot culture methods were used to first trap and isolate native species of an AMF community colonizing a heterogeneous plant community on a reclaimed coal strip mine 
site in southern West Virginia. Once each species is cultured separately, we assess (i) relative effectiveness as measured by growth response on a mycotrophic assay host and (ii) relative aggressiveness in occupying mycorrhizal roots of introduced apple and grape plants over two growing seasons, based on sporulation in root trap cultures. We hypothesize that at least one of the native AMF isolates will be as effective as proven growth-promoting commercial isolates. At the community level, we hypothesize that effective fungi will dominate to the extent that the net effect of the symbiosis on the plant community will be positive.

\section{MATERIALS AND METHODS}

\section{Site conditions}

The study site originally was a coal strip-mine in Mingo County, West Virginia. Sampling began two years after reclamation, and the plant community consisted of a hydroseeded mixture and volunteer species from the surrounding area. Native plants were collected from the four corners and center of two one-acre plots in July, 1995 and June and October, 1996. Plants were identified in situ or transported to the laboratory and stored in a cold room until they could be later identified using keys by Strausbaugh and Core (1978) (Table 1).

In May 1995, three varieties of apple (Malus x domestica Borkh.) were transplanted in

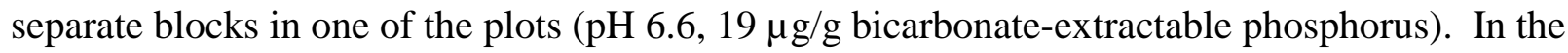
other plot, seven grape (Vitis spp.) varieties were transplanted into separate blocks ( $\mathrm{pH} 7.9,35$ $\mu \mathrm{g} / \mathrm{g}$ bicarbonate-extractable phosphorus). At the time of planting, bare roots of each plant were surrounded with 20 liters of peat moss mixed with 0.2 liters of pot-cultured inoculum with or without mycorrhizal fungi. Two mycorrhizal inoculants were formulated from pot cultures of selected AMF grown for 4 months on sudangrass [Sorghum sudanense (Staph.) Piper] in 15-cm diam pots and a sand:soil mix $(2: 1 \mathrm{v} / \mathrm{v}), \mathrm{pH} 6.2,<10 \mathrm{mg} \mathrm{kg}^{-1} \mathrm{P}$. Two mycorrhizal inoculants were used: (i) a mixture of Glomus clarum and G. etunicatum isolates used at one time as commercial inoculants by Bioplanta, Inc. (Campinas, Brazil) and Native Plants Inc. (Salt Lake City, Utah), respectively; and, (ii) a mixture of G. clarum and G. claroideum produced in trap pot cultures using rhizosphere soil from the study site as inocula. The nonmycorrhizal control consisted of the chopped contents of 4-month-old pot cultures in which no mycorrhizal fungi were present. The three inoculant treatments were randomized within the variety block of each plant species.

\section{Fungal infectivity on site}

Base-line infectivity of native AMF was estimated by a "mean infection percentage" (MIP) bioassay (Moorman and Reeves, 1979). Rhizosphere soil samples were collected from each of the four corners of apple and grape plots. Within each plot, paired samples from the eastern corners and paired samples from the western corners were pooled separately. Parallel MIP assays were carried out with separate diluent from apple and grape plots. Soil samples from each plot were mixed, passed through a 7-mm sieve, mixed 1:2(v/v) with a \# 3 quartzite sand (Penn Glass Company, Berkeley Springs, WV) and steam-sterilized once at $100^{\circ} \mathrm{C}$ for 90 minutes. Each of the pooled samples from the apple and grape plots were diluted 1:10 (v/v) with 
their respective diluents and placed in 4 x 21-cm Cone-tainers ${ }^{\mathrm{TM}}$ (Stuewe and Sons, Corvallis, OR). Each cone-tainer was overseeded with red clover (Trifolium pratense L.), and thinned to three seedlings per cone after emergence. All cone-tainers were arranged in a complete randomized block in a growth room with ambient temperature ranging from $21-28^{\circ} \mathrm{C}$ and 245 $\mu \mathrm{mol} \mathrm{m} \mathrm{s}^{-1}$ PAR for $12 \mathrm{hrs}$ each day. Rhizobium trifolii (LiphaTec, Inc., Milwaukee, WI) was watered into each cone-tainer as a suspension after seedling emergence. Roots were harvested from each cone-tainer after 35-days growth, cleared for 5 minutes in $10 \% \mathrm{KOH}$ heated to boiling, acidified for 5 minutes in $2 \% \mathrm{HCl}$, and stained for 3 minutes in $0.05 \%$ Direct Blue heated to boiling (modified from Phillips and Hayman, 1970). Percentage mycorrhizal colonization was measured by the grid-line intercept method (Giovannetti and Mosse, 1980).

\section{Isolation of native AMF}

Trap pot cultures of rhizosphere soil collected from native plants in the apple and grape plots were started in July 1995 according to standard culture methods (Morton et al., 1993). Briefly, each sample was mixed 1:1 (v/v) with coarse sterile sand, placed in 7 x 25-cm deepots (Stuewe and Sons, Corvallis, OR), overseeded with sudangrass, and grown in a greenhouse for four months, with ambient temperature ranging from $19-30^{\circ} \mathrm{C}$ and $245 \mu \mathrm{mol} \mathrm{m}^{-2} \mathrm{~s}^{-1}$ PAR for 14 hrs each day. Spores from each culture were collected by wet sieving (38- and $500-\mu \mathrm{m}$ sieves) and centrifuging in 20-60\% sucrose gradients at $900 \mathrm{x}$ g for $2 \mathrm{~min}$ (Daniels and Skipper, 1982). Different spore morphotypes were identified by stereo and compound microscopy. Spores of each morphotype were collected manually and pipetted directly onto roots of 10-day-old sorghum [Sorghum bicolor (L.) Moench.], and transplanted to cone-tainers containing a sandy loam soil (Lily series, pH 6.2, $<8 \mathrm{mg} \mathrm{kg}^{-1} \mathrm{P}$ ) mixed 1:1 (v/v) with sterile \#3 quartzite sand. Ten AMF species were successfully isolated and cultured (Table 2). Pot culture inocula of two former commercial isolates, G. etunicatum UT316 (Native Plants Inc., Utah) and G. clarum BR147B (Bioplanta, Inc., Brazil), were increased concurrently as positive mycorrhizal controls.

\section{Relative effectiveness of native AMF}

In this study, effectiveness is measured by relative growth response on a common host species following equalization of inoculum infectivity. Infectivity of all fungal isolates was equalized based on data from MIP assays. Sieved soil from the apple plot was mixed 1.5:1 (v/v) with \#3 quartzite sand, steam-sterilized for one hour on two consecutive days. The resultant diluent had a $\mathrm{pH}$ of $7.1,19 \mathrm{mg} \mathrm{kg}^{-1} \mathrm{P}$, and $<1 \%$ organic matter. A bacterial suspension from the unsterilized soil was prepared by placing $500 \mathrm{~cm}^{3}$ soil in $4 \mathrm{~L}$ tap water, incubating overnight at room temperature, and sieving to $<14 \mu \mathrm{m}$. This solution was added to the growth medium at a rate of $60 \mathrm{ml}$ solution/kg soil. Each AMF isolate was mixed with this diluent at 1:10 (v/v), placed in three $4 \times 21-\mathrm{cm}$ cone-tainers, and watered again with $10 \mathrm{ml}$ of the native bacterial suspension. Cone-tainers were overseeded with red clover and each was thinned to three seedlings after emergence. Rhizobium trifolii was added as a suspension $\left(10 \mathrm{~cm}^{3}\right.$ of LiphaTec inoculum per 0.5 $\mathrm{L} \mathrm{dH}_{2} \mathrm{O}$ ) at a rate of $6 \mathrm{ml}$ per cone-tainer. All cone-tainers were completely randomized in a growth room under temperature and light conditions described previously and grown for 21 days. Percentage mycorrhizal colonization in harvested roots was determined as described previously. Quantification of faintly staining mycorrhiza by some fungal species (G. occultum, 
G. brasilianum, G. eburneum) was determined further by examining intersections viewed through a compound microscope (McGonigle et al., 1990).

Based upon relative differences in colonization from MIP assays, inocula of AMF isolated were diluted so that all were of similar infectivity. Diluent was the same as that used in the MIP assays. Inoculum of each fungal isolate was mixed with diluent 1:10 (v/v) and then placed in deepots, with five replicates per AMF isolate. Four control inoculants were prepared (see above) for use in this experiment: (i) no mycorrhizal fungi; (ii) G. etunicatum UT316; (iii) G. clarum BR147B; and, (iv) a mixture of the G. etunicatum and G. clarum isolates. Deepots were overseeded with red clover and thinned to three seedlings per pot after emergence. Rhizobium trifolii was added as a suspension $\left(5 \mathrm{~cm}^{3}\right.$ LiphaTec inoculum/L water) at a rate of 11 $\mathrm{ml}$ per deepot. Sterile sand was layered on soil surfaces to minimize moisture loss. Pots were arranged in a completely randomized design in a growth room under the temperature and light conditions described previously. Deepots were re-randomized at the mid-point of the experiment. Plants were harvested after 49 days because of the onset of flowering and concomitant change in carbon allocation patterns. At harvest, shoots were excised at the soil line and oven-dried at $60^{\circ} \mathrm{C}$. Roots were gently removed from soil in a large volume of water, washed, and blotted dry to measure fresh weight. A $0.1 \mathrm{gm}$ (fw) subsample of roots was collected and set aside for staining. Remaining roots were dried at $60^{\circ} \mathrm{C}$ and reweighed. Contents of deepots of each fungal isolate were pooled and spores were extracted to verify identity and purity of the fungus added at the beginning of the experiment.

Foliar P was analyzed by the Kjedahl procedure (Lowther, 1980). Leaf tissue was digested with concentrated sulfuric acid $\left(\mathrm{H}_{2} \mathrm{SO}_{4}\right)$ and hydrogen peroxide $\left(\mathrm{H}_{2} \mathrm{O}_{2}\right)$ in a block digester and total $\mathrm{P}$ was measured by flow injection analysis colorimetry in a Lachat Quickchem 8000L (Zellweger Analytics, Milwaukee, WI). When sample size was too small, leaf tissue from replicates was pooled.

Percentage mycorrhizal colonization was determined from three of the five replicates by the grid-line method after staining (described previously). Total root length was calculated as the product of sample root length and ratio of total sample to subsample root dry weight (Newman, 1966). Mycorrhizal root length of each plant then was estimated as the product of percentage colonization and total root length. Mean values and standard errors were calculated for all measurements.

\section{Composition of the AMF community in field-grown apple and grape}

Roots of the three apple varieties (Golden Delicious, Fuji, and Gingergold) were sampled at the end of the first growing season (Sept. 1995) and during the second growing season (June, 1996 and Oct. 1996). Roots of three of the seven grape varieties (Aurore, Catawba, and Chardonnay) were sampled on the same dates in 1996, but were not sampled in 1995 because of insufficient root mass. A shovel was used to find pockets of fine roots, and two root samples were collected randomly from each inoculated or non-inoculated treatment. Amounts of apple and grape roots collected from each plant varied greatly $(0.14-7.05 \mathrm{~g}$ and $0.07-2.81 \mathrm{~g}$ fresh weight, respectively). 
The potting medium used to set up root trap cultures consisted of a forest soil (Lily series, $0.9 \%$ organic matter, $\mathrm{pH} 5.5,8.0 \mu \mathrm{g} / \mathrm{g}$ bicarbonate-extractable phosphorus) mixed with \#3 Quartzite sand 1:2 (v/v). This mixture was steamed for two one-hour periods at $100^{\circ} \mathrm{C}$ on two consecutive days. Each root sample was gently washed, chopped into $2-3 \mathrm{~cm}$ pieces, and placed in $150-250 \mathrm{ml}$ of potting medium. The mix containing root fragments was banded in the middle of 7 x 25-cm deepots and seeded with sudangrass [Sorghum sudanense (Staph.) Piper]. Plants were grown in a greenhouse under conditions described previously. Contents of deepots were sampled after 4 months. A section of deepot contents was manually removed $\left(75-80 \mathrm{~cm}^{3}\right)$ and spores were extracted as described previously. AMF species were identified from spore morphological structure and organization (Morton, 1988) and comparison of properties with reference isolates from INVAM (Morton et al., 1993) and species descriptions (Schenck and Perez, 1990). In each trap culture, species richness was determined and the dominant fungus was ascertained by relative numerical abundance of spores. Root colonization of apple and grape in the field was determined at the end of the second growing season, as described previously, after clearing roots for 10 minutes in $\mathrm{KOH}$ heated to boiling, bleaching for 15 minutes (10\% sodium hypochlorite), acidifying ( $2 \% \mathrm{HCl}$ ) for 15 minutes, and staining for 10 minutes with Direct Blue heated to boiling. Root sample size was $0.45 \mathrm{~g}$ fresh weight.

\section{Aggressiveness and host preference of a community of selected native AMF}

In order to determine the aggressiveness of AMF together as a "community" in a more controlled greenhouse environment, native isolates of $G$. intraradices, $G$. brasilianum, $G$. clarum, G. claroideum, and Glomus sp. WV218 were selected. Dominance by certain AMF species in field-collected roots suggested some evidence of host preferences impacting on species composition. Therefore, three plant species were used as hosts exposed to the formulated fungal community. Apple (Golden Delicious; rootstock EMLA 7; \#2 size; Adams County Nursery, Inc., Aspers, PA) represented a plant with a woody root system. Rootstock EMLA 7 was the same rootstock grafted to Golden Delicious and Fuji varieties planted in the field. Corn (Zea mays L.) represented a $\mathrm{C} 4$ grass with an extensive fibrous root system, and red clover represented a C3 legume with a taproot and moderately fibrous root system.

The potting medium consisted of steamed soil from the apple plot mixed with \#3 Quartzite sand 1.5:1 (v/v). Native bacteria in the raw soil were reintroduced as described previously. Plants were added to two inoculum treatments. The first consisted of inoculum of each fungus mixed thoroughly with the potting medium in dilutions ranging from 1/20 to $1 / 50$ to equalize infectivity (from MIP assays). The second consisted of the equalized mixture diluted $1 / 5(\mathrm{v} / \mathrm{v})$ with the potting medium. Five replicates of each dilution were prepared for each of the three host species. Apple trees were transplanted into 2-L plastic bottles filled to $1500 \mathrm{~cm}^{3}$ with inoculum mixture. Each bottle was modified with drain holes and complete coverage with duct tape to reduce algal growth. Corn was started from surface-sterilized seed, with one seed planted into each 7 × 25-cm deepot. Red clover was overseeded into 5 x 18-cm deepots (Stuewe and Sons, Inc., Corvallis, OR). Rhizobium trifolii was added as a suspension $\left(20 \mathrm{~cm}^{3}\right.$ LiphaTec inoculum/L water) at a rate of $25 \mathrm{ml}$ per deepot. 
All host species were grown in a greenhouse for three months with ambient temperature ranging from $19-32^{\circ} \mathrm{C}$ and $285 \mu \mathrm{mol} \mathrm{m}{ }^{-2} \mathrm{~s}^{-1} \mathrm{PAR}$ for $16 \mathrm{hrs}$ each day. Roots were removed from each pot, and attached soil was removed by gentle shaking. For each host species, root samples from three of the five replicates were chopped into $2-3 \mathrm{~cm}$ fragments, thoroughly mixed with 500 $\mathrm{cm}^{3}$ of potting medium used for previous root trap cultures, and placed in 7 x $25-\mathrm{cm}$ deepots. Amount of roots ( $\mathrm{fw}$ ) added to each deepot varied with host species: $18 \mathrm{~g}$ for apple; $1.4-3.3 \mathrm{~g}$ for red clover; and, 2.5-8.6 g for corn. All deepots were heavily seeded with sudangrass (40-50 seeds), and grown for four months under greenhouse conditions similar to those in which the three host species were grown. At harvest, spores were extracted (as described previously) from $50 \mathrm{~cm}^{3}$ samples removed from each pot. Spores per $\mathrm{cm}^{3}$ potting medium of each fungal species present were enumerated under a stereomicroscope as described previously.

\section{Statistical analyses}

In effectiveness assays, one-sided planned comparisons using Dunnett's test (Dunnett, 1955 ) with critical $\alpha=0.05$ were employed to compare each native AMF species with each of the four control treatments. The dependent measures of shoot dry weight, foliar P concentration, root dry weight, and mycorrhizal root length were analyzed. Mycorrhizal root length measurements were log-transformed to obtain homogeneity of variance. For each dependent variable, the four control treatments were compared using a one-way analysis of variance (ANOVA), followed by post-hoc testing using two-tailed independent groups Student's t-tests.

Correlation analyses were performed for the shoot dry weight versus foliar $\mathrm{P}$ concentration in the effectiveness assays, and for root dry weight versus number of AMF species sporulating in apple and grape root trap cultures. For field colonization measurements, two-way ANOVAs analyzing host variety and mycorrhizal treatment (inoculated or non-inoculated) were calculated; colonization measurements were transformed to obtain homogeneity of variance using an arcsine-square root calculation. For analysis of a formulated native AMF community, spore density was analyzed relative to AMF species, host species, and inoculum dilution in a three-way ANOVA. Calculations were carried out with the aid of JMP ${ }^{\circledR}$ (SAS Inst., Inc., 1995).

\section{RESULTS}

\section{Composition of native AMF community}

Fourteen species of AMF were found on the reclaimed coal strip mine site in Mingo County, West Virginia. Most were recovered from trap cultures of rhizosphere soil of the heterogeneous established plant community (Table 1). All were established successfully in monospecific cultures except for Scutellospora dipurpurascens Morton \& Koske, Acaulospora trappei Ames \& Linderman, G. aggregatum Schenck \& Smith, and G. microaggregatum Koske, Gemma \& Olexia. Infectivity of rhizsophere soil samples containing this fungal community was high based on mean colonization in 35-day-old MIP assays. Colonization averaged $44 \%$ and $30 \%$ in samples from the apple and grape plots, respectively. 


\section{Relative effectiveness of native AMF}

The ten native fungal species that were established separately in pot cultures (Table 2) were compared for their relative effectiveness to promote growth of a mycotrophic assay host, red clover. These fungi differed considerably in growth responses (Fig. 1, Table 3). Glomus occultum Walker, G. luteum Kennedy, Stutz \& Morton, and G. diaphanum Morton \& Walker did not vary significantly from the negative control, and thus were considered ineffective growth promoters. Glomus brasilianum Spain \& Miranda was of intermediate effectiveness. Glomus eburneum Kennedy, Stutz \& Morton, G. claroideum Schenck \& Smith, Glomus sp. WV218, G. clarum Nicolsen \& Schenck, G. intraradices Schenck \& Smith, and Glomus sp. WV214B, were at least as effective as G. clarum BR147B, the most effective positive control.

Mean foliar P concentrations in red clover with all AMF except G. occultum were equal to or significantly greater than in red clover with the two positive control fungi (Fig. 1, Table 3). The foliar P of red clover colonized by G. clarum BR147B did not differ significantly from that of nonmycorrhizal plants ( $\mathrm{p}>0.05$ ). Of the three ineffective growth promoters, G. luteum led to one of the highest levels of foliar P content (Fig. 1). Therefore, it is not surprising that shoot dry weight and foliar $\mathrm{P}$ concentration were not correlated significantly $(\mathrm{p}>0.05 ; \mathrm{r}=0.015)$.

Differences in red clover root dry weight paralleled that of shoot biomass, so that rankings of ineffective and effective native AMF also were similar (Table 3). Of the ten fungal species, only the native $G$. clarum and $G$. intraradices isolates produced mycorrhizal root lengths similar to that of G. clarum BR147B positive control. Mycorrhizal root length of all AMF tested was equal to or greater than that of $G$. etunicatum UT316 positive control.

The mixture of G. clarum BR147B and G. etunicatum UT316 appeared to enhance shoot dry weight and foliar P concentration additively (Fig. 1, Table 3). However, shoot dry weight was not significantly different from that of G. clarum BR147B ( $\mathrm{p}>0.05$ ), and foliar P concentration and root dry weight were not significantly different from G. etunicatum UT316 (p $>0.05$ ). Mycorrhizal root length for the mixed inoculum was significantly less than that of $G$. clarum BR147B ( $<$ 0.05).

\section{Composition of AMF community in field-grown apple and grape}

Apple and grape varieties transplanted into plots were 83-99\% mycorrhizal by the end of the second growing season. Colonization levels were not significantly different for inoculated and non-inoculated plants $(\mathrm{F}=1.3820, \mathrm{p}>0.05$ for apple; $\mathrm{F}=4.5924, \mathrm{p}>0.05$ for grape), indicating high inoculum potential by native AMF. Of the introduced fungi, G. claroideum was not detected in any apple or grape root trap cultures. Glomus etunicatum, which comprised approximately $80 \%$ of sporulation in one inoculum, was detected in only one trap culture from apple roots (Fig. 2). Glomus clarum was isolated in 16 apple trap cultures (Fig. 2). Five were from noninoculated plants (data not shown), and therefore contained a native G. clarum isolate. All other cultures were from inoculated plants, so the G. clarum present was either the native isolate, the introduced isolate, or a mixture of both isolates. 
Such high levels of mycorrhizal colonization (see above) indicated that roots from apple and grape plants collected in the field provided an infective source of inoculum of colonizing fungal species. Ten species of arbuscular mycorrhizal fungi were isolated from these root trap cultures (Fig. 2). More AMF species were recovered from apple cultures over two growing seasons (10 species) than the grape cultures from the second growing season (5 species). A second propagation cycle of inoculum from selected apple and grape root trap cultures failed to produce sporulation by any additional AMF species. Mean sporulation in all cultures started from the June and October 1996 samples was 4.4 spores $\mathrm{cm}^{-3}$ and 12.9 spores $\mathrm{cm}^{-3}$, respectively. Root dry weight and number of AMF species sporulating in each trap culture were not significantly correlated.

Glomus intraradices was recovered from most trap cultures of apple and grape roots at all sampling dates (Fig. 2). Of the AMF species detected in roots, only G. aggregatum was not successfully established in monospecific culture. This species, however, is morphologically plastic and tends to become indistinguishable from $G$. intraradices after culturing (Morton, unpubl.). Two of the three ineffective species, G. occultum, and G. luteum (Fig. 1, Table 3), were recovered only rarely, and then only from apple roots (Fig. 2). Two of the effective isolates obtained from initial trap cultures of established plants, G. claroideum and Glomus sp. WV214B, were not detected in apple or grape roots, and G. eburneum was detected in only one culture. Glomus clarum was recovered only from apple roots.

In addition to the frequency of occurrence of $G$. intraradices in trap cultures, this fungus also appeared to be the most aggressive. Sporulation by this fungus dominated in $100 \%$ of the grape root cultures and in over $78 \%$ of apple root cultures (Fig. 3). Of the four AMF species dominating in individual cultures (Fig. 3), G. clarum and G. intraradices were highly effective and G. brasilianum was of intermediate effectiveness (Fig. 1, Table 3). Only G. diaphanum was ineffective (Fig. 1, Table 3).

\section{Aggressiveness and host preference of a community of selected native AMF}

Of the five native AMF species in a formulated community propagated on three host species, only G. clarum, G. brasilianum, and G. intraradices were recovered from trap cultures of host root systems. Relative spore density of each fungal species differed among hosts (Fig. 4). Glomus clarum sporulated more profusely than other AMF species from corn roots ( $<<0.0001)$. Both G. clarum and $G$. intraradices were the dominant sporulators from red clover roots ( $\mathrm{p}<$ 0.0025). Glomus brasilianum was the dominant sporulator from apple roots $(\mathrm{p}<0.006)$. A visual inspection of stained mycorrhizal roots from trap cultures of the three host species verified some linkage between amount of root occupied and abundance of sporulation. Both G. clarum and G. intraradices are intraradical sporulators, and each can be distinguished in roots by intraradical hyphal diameters and size of spores (Morton, 1988). Spores of G. clarum dominated in corn roots, whereas $G$. intraradices spores were widely distributed in red clover roots (data not shown). Glomus brasilianum, in contrast, produces no intraradical spores or vesicles and all intraradical fungal structures stain only faintly (Morton, unpubl.). Apple roots showed few darkstaining mycorrhiza, confirming this species as the dominant colonizer. Inoculum dilution had no significant effect on host preference $(F=0.0888, \mathrm{p}>0.05)$. 


\section{DISCUSSION}

To our knowledge, this study is the first to exhaustively dissect a community of AMF and to characterize the component isolates relative to commercial isolates. The native AMF community was complex, consisting of fourteen species recovered from trap cultures. This level of taxonomic diversity is not unusual. Gould and Hendrix (1998) observed only 3-4 AMF species sporulating in the first two years of plant reintroduction to five abandoned surface coal mines in western Kentucky, but measured ten AMF species at the end of five years. In apple orchards throughout the United States, species richness ranged from 3 to 8 (Miller et al., 1985). From grasslands to sand dunes, species richness ranges from 12-21 species, with much of the variation attributable to sampling strategies (Morton et al., 1995). Additional species richness may have been obtained from the Mingo County plots with the use of more extensive culturing protocols (Bever et al., 1996). Considerable evidence exists to indicate that a threshold level of colonization is necessary to trigger sporulation (Gazey et al., 1992; Pearson and Schweiger, 1993; Franke and Morton, 1994; Chapter 2).

All ten isolates tested in the effectiveness assays were aggressive colonizers in greenhouse pot cultures, producing a mycorrhizal root length equal to or greater than that for the G. etunicatum UT316 positive control. Comparing isolates of the same species, mycorrhizal root length of the native $G$. clarum was as high as that of the G. clarum BR147B positive control. In contrast, symbiotic effectiveness, as measured by growth benefit to red clover, was more diverse. At least $60 \%$ of the native fungal isolates were as or more effective than the most effective positive control and $70 \%$ were as or more effective than the least effective positive control.

Three species did not vary significantly from the nonmycorrhizal control in shoot biomass, but one species, G. luteum, was in the effective range for foliar P uptake. Shoot biomass and foliar P concentration did not correlate significantly, a pattern observed in other host-fungal interactions (e.g., Sylvia et al., 1993). Part of the autonomy between the two variables may be the unique source-sink relationships for red clover and other legumes. Nitrogen fixation has a high phosphorus requirement (Barea and Azcon-Aguilar, 1983; Morton et al., 1990), and patterns in the partitioning of $\mathrm{P}$ between roots and shoots were not measured in this study.

Glomus intraradices was the most aggressive species in the native AMF community, as determined by distribution and abundance of sporulation in apple and grape root trap cultures. While abundance of sporulation may not accurately quantify the amount of root colonized by the fungus (Scheltema et al., 1987; Giovanetti et al., 1988; Brundrett, 1991; Pearson and Schweiger, 1993), it indicates sufficient root occupation to afford luxury allocation of carbon resources to both sporulation and colonization rather than colonization alone (Morton et al., 1995). On the other hand, sporulation and mycorrhizal development are directly correlated in some host-fungus combinations (Gazey et al., 1992; Franke and Morton, 1994; Chapter 2). In any case, the considerable aggressiveness of $G$. intraradices in trap cultures was corroborated by evidence of abundant intraradical sporulation in field-collected roots that is typical of the species (Schenck and Smith, 1982). 
Glomus intraradices and other aggressive AMF species at the study site also were the most effective in promoting red clover growth. Not all effective AMF isolates in the native community, however, were aggressive colonizers under these field conditions. Three of the effective fungi, G. claroideum, Glomus sp. WV214B, and G. eburneum, were rarely or never detected in trap cultures of apple or grape roots over two growing seasons. They were still present, but more likely were colonizers of other plants present in plots that persisted from the original plant community. These results indicate the effectiveness and aggressiveness are not tightly linked, and that each must be evaluated separately when evaluating properties of AMF fungal isolates.

When aggressiveness and effectiveness of components of the native AMF community are considered together, then a net positive benefit would be expected in field-grown plants at the study site, since a majority of the most aggressive fungi were also highly effective growth promoters. The two most ineffective fungal isolates were rarely detected in root trap cultures, indicating they were either absent or had not produced sufficient biomass to sporulate. Additive growth benefits can be obtained when native or introduced inocula are mixtures of AMF isolates (Morton et al., 1995; Schreiner and Bethlenfalvay, 1996; Koomen et al., 1988). In this study, mixtures of native fungi were not tested for collective effectiveness in promoting plant growth. However, red clover responses to two commercial fungal isolates (G. etunicatum UT316 and $G$. clarum BR147B) were examined together relative to each isolate separately. In this assay, the combination of fungi produced a growth response that was not significantly different from that of the more effective isolate ( $G$. clarum BR147B). Trap cultures of roots from the combined versus separate inoculants were not initiated, so it is not clear whether both fungi in the mix cocolonized equally or if one of the species dominated in the mycorrhizae. The two fungi together did not produce the amount of mycorrhizae observed for G. clarum BR147B alone, suggesting that the less aggressive G. etunicatum may have been more of a factor in the red clover growth response.

Characterization of effectiveness and aggressiveness of the native fungal community at the experimental site used in this study so far has been limited to responses for a single host species (red clover). Comparisons of the same AMF isolates on different host species and in different greenhouse environments suggest that fungal genotype may be more important than either host or soil variables in mycorrhizal growth responses (Sylvia et al., 1993). However, their study did not take into consideration differences in aggressiveness among AMF in a complex community, which is the norm rather than the exception. It appears that a useful strategy for inoculum production would be to first look for aggressive isolates, then see if they are effective on the target host species.

The preponderance of $G$. intraradices in apple and grape roots when such a diverse AMF community existed on the established plant community (Fig. 1) suggested some host selectivity or preference. Arbuscular mycorrhizal fungi are not considered to be host-specific (Smith and Read, 1997), but this conclusion is complicated by scale. At the level of the individual plantfungus interaction, a single host species such as sudangrass or corn can support the full taxonomic and ecological range of AMF (Morton et al., 1993; Morton, 1999). At the level of the 
plant and fungal communities, differential host compatibility has been reported as a function of differential sporulation (Bever et al., 1996; del Val et al., 1999). These patterns appear to be more affected by host-dependent differences on fungal population growth rates rather than timing of sporulation. Host preference effects also are noted in AMF communities that change with differences in plant species composition either by natural succession (Sanders and Fitter, 1992) or by cropping history (An et al., 1993; Guo et al., 1994; Hendrix et al., 1995).

In this study, selected members of native AMF with near equivalent levels of infectivity were combined into a new community. Glomus intraradices, G. brasilianum, and G. clarum were chosen because they were the three most aggressive species isolated from apple and grape root trap cultures. Glomus claroideum and Glomus sp. WV218 were chosen as less aggressive colonizers. When the roots from corn, red clover, and apple grown with this fungal community under greenhouse conditions were used as inoculum in trap cultures, only the three aggressive species produced any sporulation in the root cultures. Surprisingly, each fungus differentially sporulated from roots of each host species, but in a pattern that was not completely in congruence with observed distribution of fungi in the field. Glomus clarum dominated in corn both in the greenhouse experiment and in the field (results not shown), and codominance by G. clarum and $G$. intraradices in red clover roots conformed to their presence in forage legumes at the field site. In contrast, $G$. intraradices appeared to dominate in field-grown apple, however in the greenhouse experiment, colonization by this species was so low that few spores were produced. Conversely, G. brasilianum appeared to dominate in the greenhouse-grown apple, but this species was less frequently detected in field-collected root samples. The sporulation patterns in sudangrass root trap cultures were considered reliable measures of differential colonization, since mycorrhiza morphologies of the three species sporulating are somewhat distinct and could be crudely assayed for dominance in roots of each host species. The use of mycorrhizal morphology as a direct measure of fungal colonization is not new (Abbott, 1982; Abbott and Gazey, 1994; McGee, 1989), but it is useful only when the symbionts possess distinct criteria for identification.

Differences in infectivity among fungi in each community could account for the conflicting results between greenhouse and field-grown apple. Infectivity was equalized among all members of the formulated community in the greenhouse experiment, whereas it was likely highly variable in the field. If $G$. intraradices was the most infective in the field, it could override host preference effects.

In all of the trap cultures started from washed roots, whether these roots originated from field-collected samples or a greenhouse experiment, most of the dominant species (G. intraradices, G. clarum, and G. diaphanum) were intraradical sporulators (Morton, 1988). Dominance by fungi with this life history trait may be coincidence, but it also raises the possibility that the type of inoculum (roots) or the method of inoculum preparation (washing of roots to forcibly remove external hyphae and spores) may have selected for these species. If this occurred, then other nonintraradical sporulators present in mycorrhizae would not become established sufficiently to sporulate (see Chapter 2). The role of life history traits in inoculum infectivity or aggressiveness has yet to be determined experimentally. 
Ultimately, success or failure of introducing fungi into a field situation is a function of infectivity (to initiate colonization) and aggressiveness (to maintain colonization as roots proliferate). Native fungi in the study site prior to apple and grape plantings produced $44 \%$ and $30 \%$ colonization in red clover MIP assays. These values were equivalent to those of undiluted four-month-old pot cultures of fungal mixtures from a wide range of habitats (Sturmer, 1998; Morton, unpubl.), indicating high infectivity (or inoculum potential). Introduced inocula were of similar infectivity as well (mean of $41 \%$ colonization) when taken directly from production pot cultures. However, these inocula were diluted $200 \mathrm{ml}$ in $20 \mathrm{~L}$ of peat moss at the time of application to bare-rooted apple and grape during transplantation operations, with a concomitant 100 -fold reduction in infectivity. This dilution effect in the presence of a highly infective native fungal community eliminated any competitive edge by introduced fungi, even if they were as or more aggressive than the native fungi.

In conclusion, this study showed that: (i) the majority of native AMF isolates in a twoyear-old plant community were as effective as proven growth-promoting commercial isolates; and, (ii) the net benefit of native colonizing fungi likely was positive, since the majority of the fungi colonizing apple and grape roots in the field also were effective symbionts. These conclusions corroborate results of other studies (Abbott and Robson, 1981; Menge, 1983), showing the autonomy between effectiveness responses in plants and aggressiveness responses by the fungus-host interaction. 


\section{REFERENCES}

Abbott, L. K. 1982. Comparative anatomy of vesicular-arbuscular mycorrhizas formed on subterranean clover. Australian Journal of Botany 30:485-499.

Abbott, L. K., and C. Gazey. 1994. An ecological view of the formation of VA mycorrhizas. Plant and Soil 159:69-78.

Abbott, L. K. and A. D. Robson. 1981. Infectivity and effectiveness of five endomycorrhizal fungi: Competition with native fungi in field soils. Australian Journal of Agricultual Research 32:621-630.

Afek, U., E. Rinaldelli, J. A. Menge, E. L. V. Johnson, and E. Pond. 1990. Mycorrhizal species, root age, and position of mycorrhizal inoculum influence colonization of cotton, onion and pepper seedlings. Journal of the American Society of Horticultural Science 115:938942.

An, Z.-Q., B. Z Guo, and J. W. Hendrix. 1993. Mycorrhizal pathogen of tobacco: cropping history and current crop effects on the mycorrhizal fungal community. Crop Protection 12:527-531.

Barea, J. M. and C. Azcon-Aguilar. 1983. Mycorrhizae and their significance in nodulating Nfixing plants. Advances in Agronomy 36:1-54.

Bever, J. D., J. B. Morton, J. Antonovics, and P. A. Schultz. 1996. Host-dependent sporulation and species diversity of arbuscular mycorrhizal fungi in a mown grassland. Journal of Ecology 84:71-82.

Boerner, R. E. J., B. G. Demars, and P. N. Leicht. 1996. Spatial patterns of mycorrhizal infectiveness of soils long a successional chronosequence. Mycorrhiza 6:79-90.

Brundrett, M. 1991. Mycorrhizas in natural ecosystems. Advances in Ecological Research 21:171-313.

Bryla, D. R.. and R. T. Koide. 1990. Regulation of reproduction in wild and cultivated Lycopersicon esculentum Mill. by vesicular-arbuscular mycorrhizal infection. Oecologia 84:74-81.

Campbell, B. D., J. P Grime, and J. M. L. Mackey. 1991. A trade-off between scale and precision in resource foraging. Oecologia 87:532-538.

Daniels, B. A. and H. D. Skipper. 1982. Methods for the recovery and quantitative estimation of propagules from soil. In: Methods and Principles of Mycorrhizal Research, N. C. Schenck, ed. pp. 29-35. APS Press, St. Paul, Minnesota. 
del Val, C., J. M. Barea, and C. Azcon-Aguilar. 1999. Diversity of arbuscular mycorrhizal fungus populations in heavy-metal-contaminated soils. Applied and Environmental Microbiology 65:718-723.

Douds, D. D. 1994. Relationship between hyphal and arbuscular colonization and sporulation in mycorrhiza of Paspalum notatum Flugge. New Phytologist 126:233-237.

Dunnett, C. W. 1955. A multiple comparison procedure for comparing several treatments with a control. Journal of the American Statistics Association 50:1096-1121.

Eissenstat, D. M., J. H. Graham, J. P. Syvertsen, and D. L. Drouillard. 1993. Carbon economy of sour orange in relation to mycorrhizal colonization and phosphorus status. Annals of Botany 71:1-10.

Franke, M., and J. Morton. 1993. Ontogenetic comparisons of arbuscular mycorrhizal fungi Scutellospora heterogama and Scutellospora pellucida: revision of taxonomic character concepts, species descriptions, and phylogenetic hypotheses. Canadian Journal of Botany $72: 122-134$.

Gazey, C., L. K. Abbott, and A. D. Robson. 1992. The rate of development of mycorrhizas affects the onset of sporulation and production of external hyphae by two species of Acaulospora. Mycological Research 96:643-650.

Giovannetti, M., and B. Mosse. 1980. An evaluation of techniques for measuring vesicular arbuscular mycorrhizal infection in roots. New Phytologist 84:489-500.

Gould, A. B., and J. W. Hendrix. 1998. Relationship of mycorrhizal activity to time following reclamation of surface mine land in western Kentucky. II. Mycorrhizal fungal communities. Canadian Journal of Botany 76:204-212.

Guo, B. Z., Z. Q. An, and J. W. Hendrix. 1994. A mycorrhizal pathogen (Glomus macrocarpum Tul. \& Tul.) of tobacco: effects of long- and short-term cropping on the mycorrhizal fungal community and stunt disease. Applied Soil Ecology 1:269-276.

Hendrix, J. W., B. Z. Guo, and Z.-Q. An. 1995. Divergence of mycorrhizal fungal communities in crop production systems. Plant and Soil 170:131-140.

Hetrick, B. A. D., G. W. T. Wilson, and T. S. Cox. 1992. Mycorrhizal dependence of modern wheat varieties, landraces, and ancestors. Canadian Journal of Botany 70:2032-2040.

Johnson, N. C., P. J. Copeland, R. K. Crookstone, and F. L. Pfleger. 1992. Mycorrhizae: Possible explanation for yield decline with continuous corn and soybean. Agronomy Journal 84: 387-390. 
Johnson, N. C., J. H. Graham, and F. A. Smith. 1997. Functioning of mycorrhizal associations along the mutualism-parasitism continuum. New Phytologist 135:575-585.

Koomen, I., C. Grace, and D. S. Hayman. 1988. Effectiveness of single and multiple mycorrhizal inocula on growth of clover and strawberry plants at two soil pHs. Soil Biology and Biochemistry 19:539-544.

Lau, T.-C., X. Lu, R. T. Koide, and A. G. Stephenson. 1995. Effects of soil fertility and mycorrhizal infection on pollen production and pollen grain size of Cucurbita pepo (Cucurbitaceae). Plant, Cell and Environment 18:169-177.

Lowther, J. R. 1980. Use of a single sulfuric acid hydrogen peroxide digest for the analysis of Pinus radiata needles. Communications in Soil Science and Plant Analysis 11:175-188.

McGee, P. A. 1989. Vesicular-arbuscular mycorrhizal and saprophytic fungi of the swain reefs, Australia. Mycological Research 93:375-378.

McGonigle, T. P., M. H. Miller, D. G. Evans, G. L. Fairchild, and J. A. Swan. 1990. A new method which gives an objective measure of colonization of roots by vesicular-arbuscular mycorrhizal fungi. New Phytologist 115:495-505.

Menge, J. A. 1983. Utilization of vesicular-arbuscular mycorrhizal fungi in agriculture. Canadian Journal of Botany 61:1015-1024.

Merryweather, J. and A. Fitter. 1995a. Phosphorus and carbon budgets: mycorrhizal contribution in Hyacinthoides non-scripta (L.) Chouard ex Rothm. Under natural conditions. New Phytologist 129:619-627.

Merryweather, J., and A. Fitter. 1995b. Arbuscular mycorrhiza and phosphorus as controlling factors in the life history of Hyacinthoides non-scripta (L.) Chouard ex Rothm. New Phytologist 129:629-636.

Miller, D. D., P. A. Domoto, and C. Walker. 1985. Mycorrhizal fungi of eighteen apple rootstock plantings in the United States. New Phytologist 100:379-391.

Moorman, T. and F. B. Reeves. 1979. The role of endomycorrhizae in revegetation practices in the semi-arid West. II. A bioassay to determine the effect of land disturbance on endomycorrhizal populations. American Journal of Botany 66:14-18.

Morton, J. B. 1988. Taxonomy of VA mycorrhizal fungi: Classification, nomenclature, and identification. Mycotaxon 32:267-324. 
Morton J. B. 1990. Species and clones of arbuscular mycorrhizal fungi (Glomales, Zygomycetes): their role in macro- and microevolutionary processes. Mycotaxon 37:493515.

Morton, J. B. 1999. Evolution of endophytism in arbuscular mycorrhizal fungi of Glomales. In: Microbial Endophytes, C. W. Bacon and J. F. White, eds. pp. 121-140. Marcel Dekker, Inc., New York.

Morton, J. B., and G. L. Benny. 1990. Revised classification of arbuscular mycorrhizal fungi (Zygomycetes): A new order, Glomales, two new suborders, Glomineae and Gigasporineae, and two new families, Acaulosporaceae and Gigasporaceae, with an emedation of Glomaceae. Mycotaxon 37:471-491.

Morton, J. B., and S. P. Bentivenga. 1994. Levels of diversity in endomycorrhizal fungi (Glomales, Zygomycetes) and their role in defining taxonomic and non-taxonomic groups. Plant and Soil 159:47-59.

Morton, J. B., S. P. Bentivenga, and J. D. Bever. 1995. Discovery, measurement, and interpretation of diversity in arbuscular endomycorrhizal fungi (Glomales, Zygomycetes). Canadian Journal of Botany 73:S25-S32.

Morton, J. B., S. P. Bentivenga, and W. W. Wheeler. 1993. Germ plasm in the International Collection of Arbuscular and Vesicular-Arbuscular Mycorrhizal Fungi (INVAM) and procedures for culture development, documentation, and storage. Mycotaxon 48:491-528.

Newman, E. I. 1966. A method for estimating the total length of root in a sample. Journal of Applied Ecology 3:139-145.

Newsham, K. K., A. H. Fitter, and A. R. Watkinson. 1994. Arbuscular mycorrhiza protect an annual grass from root pathogenic fungi in the field. Journal of Ecology 83:991-1000.

Ollivier, B., Y. Bertheau, H. G. Heim, and V. Gianinazzi-Pearson. 1983. Influence de la variete de Vigna unguiculata dans l'expression de trois association endomycorrhiziennes a vesicules et arbuscules. Canadian Journal of Botany 61:354-358.

Pearson, J. N. and P. Schweiger. 1993. Scutellospora calospora (Nicol. \& Gerd.) Walker \& Sanders associated with subterranean clover produces non-infective hyphae during sporulation. New Phytologist 127:697-701.

Phillips, J. M., and D. S. Hayman. 1970. Improved procedures for clearing roots and staining parasitic and vesicular-arbuscular mycorrhizal fungi for rapid assessment of infection. Transactions of the British Mycological Society 55:158-161.

Pirozynski, K. A., and Y. Dalpé. 1989. Geological history of the Glomaceae with particular reference to mycorrhizal symbiosis. Symbiosis 7: 1-36. 
Powell, C. Ll., G. E. Clarke, and N. J. Verberne. 1982. Growth response of four onion cultivars to isolates of VA mycorrhizal fungi. New Zealand Journal of Agricultural Research 25:465-470.

Ravnskov, S., and I. Jakobsen. 1995. Functional compatibility in arbuscular mycorrhizas measured as hyphal P transport to the plant. New Phytologist 129:611-618.

Scheltema, M. A., L. K. Abbott, A. D. Robson. 1987. Seasonal variation in the infectivity of VA mycorrhizal fungi in annual pastures in a Mediterranean environment. Australian Journal of Agricultural Research 38:707-715.

Schenck, N. C. and G. S. Smith. 1982. Additional new and unreported species of mycorrhizal fungi (Endogonaceae) from Florida. Mycologia 74:77-92.

Schenck, N. C., and Y. Perez. 1990. Manual for the Identification of VA Mycorrhizal Fungi. Synergistic Publications, Gainesville.

Schreiner, R. P., and G. J. Bethlenfalvay. 1997. Plant and soil response to single and mixed species of arbuscular mycorrhizal fungi under fungicide stress. Applied Soil Ecology 7:93-102.

Simon, L., Bousquet, J., Lévesque, R.C., \& Lalonde, M. 1993. Origin and diversification of endomycorrhizal fungi and coincidence with vascular land plants. Nature 363:67-69

Smith, S.E. \& Read, D.J. 1997. Mycorrhizal Symbiosis. Academic Press, San Diego, CA.

Stanley, M. R., R. T. Koide, and D. L. Shumway. 1993. Mycorrhizal symbiosis increases growth, reproduction and recruitment of Abutilon theophrasti Medic. in the field. Oecologia 94:30-35.

Strausbaugh, P. D., and E. L. Core. 1978. Flora of West Virginia, $2^{\text {nd }}$ ed. Seneca Books, Inc., Grantsville, WV.

Stutz, J. C., and J. B. Morton. 1996. Successive pot cultures reveal high species richness of arbuscular endomycorrhizal fungi in arid ecosystems. Canadian Journal of Botany 74:1883-1889.

Sylvia, D. M., D. O. Wilson, J. H. Graham, J. J. Maddox, P. Millner, J. B. Morton, H. D. Skipper, S. F. Wright, and A. G. Jarstfer. 1993. Evaluation of vesicular-arbuscular mycorrhizal fungi in diverse plants and soils. Soil Biology and Biochemistry 25:705-713.

Titus, J. H., and R. del Moral. 1998. Vesicular-arbuscular mycorrhizae influence Mount St. Helens pioneer species in greenhouse experiments. Oikos 81:495-510. 
Trappe, J. M. 1987. Phylogenetic and ecological aspects of mycotrophy in the angiosperms from an evolutionary standpoint. In: Ecophysiology of VA Mycorrhizal Plants, G. R. Safir, ed. pp. 5-25. Boca Raton, Florida:CRC Press.

Wilson, D. O. 1988. Differential plant responses to inoculation with two VA mycorrizal fungi isolated form a low-pH soil. Plant and Soil 110:69-75.

Wilson, J. M. 1984. Comparative development of infection by three vesicular-arbuscular mycorrhizal fungi. New Phytologist 97:413-426. 
Table 1. Plant species composition in plots, Mingo County, West Virginia.

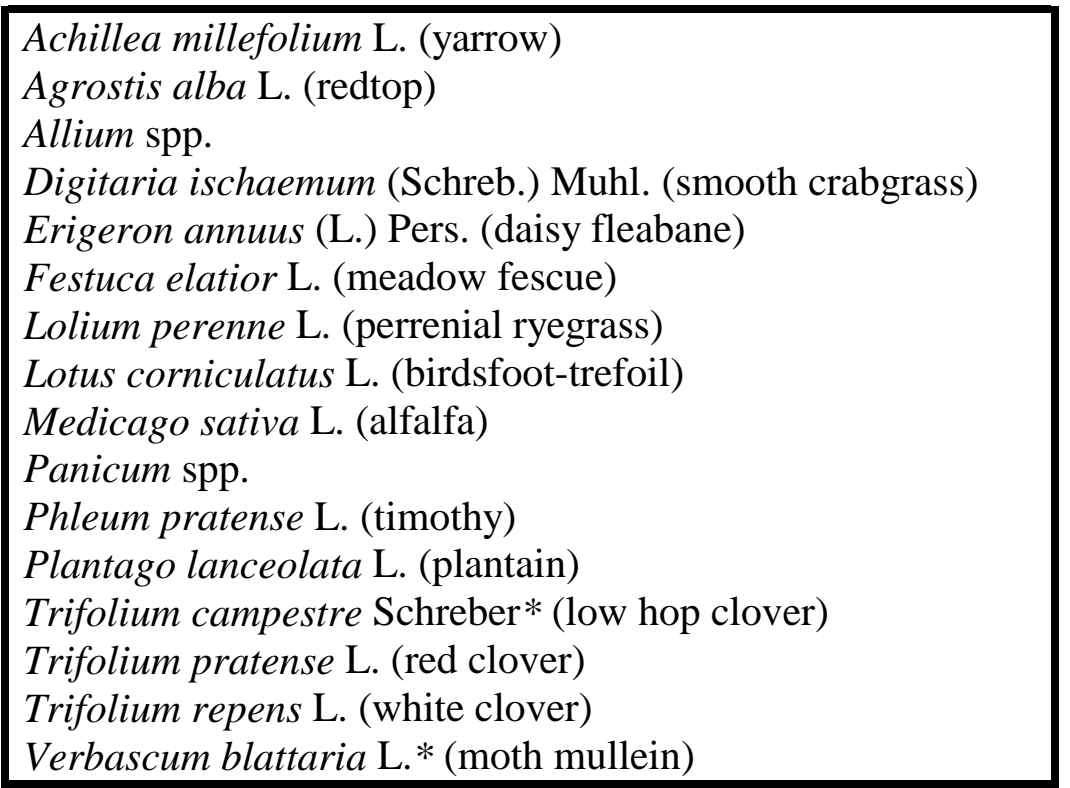

* identification equivocal 
Table 2. Native AMF species sporulating in trap cultures from field plots and successfully established in monospecific culture.

\begin{tabular}{|l|c|l|}
\hline \multicolumn{1}{|c|}{$\begin{array}{c}\text { AMF } \\
\text { Species }\end{array}$} & $\begin{array}{c}\text { INVAM } \\
\text { Accession } \\
\text { Number }\end{array}$ & \multicolumn{1}{|c|}{$\begin{array}{c}\text { Location } \\
\text { Trapped From }\end{array}$} \\
\hline Glomus occultum Walker & WV211B & SW quadrant of apple plot \\
\hline G. luteum Kennedy, Stutz \& Morton & WV216A & NW quadrant of grape plot \\
\hline G. diaphanum Morton \& Walker & WV221 & apple root trap \\
\hline G. brasilianum Spain \& Miranda & WV212 & preliminary traps in the area \\
\hline G. eburneum Kennedy, Stutz \& Morton & WV216B & NW quadrant of grape plot \\
\hline G. claroideum Schenck \& Smith & WV220 & center of grape plot \\
\hline Glomus sp. WV218 & WV218 & preliminary traps in the area \\
\hline G. clarum Nicolson \& Schenck & WV219 & preliminary traps in the area \\
\hline G. intraradices Schenck \& Smith & WV230 & traps of apple and grape roots \\
\hline Glomus sp. WV214B ${ }^{2}$ & WV214B & NE quadrant of grape plot \\
\hline
\end{tabular}

${ }^{1}$ Spores are white to pale yellow colored and 60-140 $\mu \mathrm{m}$ in diameter. Spore wall structure resembles that of $G$. claroideum, except layers can by hyaline and outer layer does not react in Melzer's Reagent.

${ }^{2}$ Spores are pale brown-yellow and $60-110 \mu \mathrm{m}$ in diameter, with a spore wall structure resembling that of $G$. claroideum. 
Table 3. Responses (mean \pm SE) of 7-week-old red clover plants to colonization by ten native isolates, a negative control, and positive controls (commercial isolates UT316 and BR147B alone or combined). Native isolates were compared to controls using one-tailed Dunnett's tests $(\mathrm{P}=0.05)$. Mycorrhizal root length $(\mathrm{MRL})$ data was log-transformed prior to analysis. Within each column, native isolates that were not significantly greater than the negative control are labeled (a), and those that were not significantly less than the three positive controls are designated as (b), (c), or (d).

\begin{tabular}{|c|c|c|c|c|c|c|c|c|c|c|}
\hline \multirow{2}{*}{$\begin{array}{c}\text { Controls/ } \\
\text { Native } \\
\text { Isolates } \\
\text { none }\end{array}$} & Species & \multicolumn{2}{|c|}{$\begin{array}{l}\text { Shoot Dry Wt. (g) } \\
\qquad n=5\end{array}$} & \multicolumn{3}{|c|}{ Foliar P (mg g $\left.{ }^{-1}\right)$} & \multicolumn{2}{|c|}{$\begin{array}{c}\text { Root Dry Wt. (g) } \\
n=5\end{array}$} & \multicolumn{2}{|c|}{$\begin{array}{l}\text { MRL (m) } \\
\quad \mathbf{n}=\mathbf{3}\end{array}$} \\
\hline & none & $0.06 \pm 0.01$ & $\mathrm{a}$ & $0.86 \pm 0.26$ & $\mathrm{n}=2$ & $\mathrm{a}$ & $0.01 \pm 0.00$ & $\mathrm{a}$ & $0.00 \pm 0.00$ & $\mathrm{a}$ \\
\hline UT316 & G. etunicatum & $0.18 \pm 0.02$ & $\mathrm{~b}$ & $1.36 \pm 0.10$ & $\mathrm{n}=4$ & $\mathrm{~b}$ & $0.04 \pm 0.00$ & $\mathrm{~b}$ & $1.60 \pm 0.15$ & $\mathrm{~b}$ \\
\hline BR147B & G. clarum & $0.28 \pm 0.02$ & $\mathrm{c}$ & $1.14 \pm 0.10$ & $\mathrm{n}=5$ & $\mathrm{c}$ & $0.07 \pm 0.01$ & $\mathrm{c}$ & $10.27 \pm 1.98$ & $\mathrm{c}$ \\
\hline $\begin{array}{l}\text { BR147B } \\
+ \text { UT316 }\end{array}$ & $\begin{array}{l}\text { G. etunicatum } \\
+ \text { G. clarum }\end{array}$ & $0.30 \pm 0.02$ & & $1.57 \pm 0.13$ & $\mathrm{n}=5$ & d & $0.05 \pm 0.00$ & & $6.27 \pm 0.55$ & \\
\hline "WV211B & G. occultum & $0.05 \pm 0.01$ & & 0.47 & $\mathrm{n}=1$ & $\overline{\mathrm{a}}$ & $0.02 \pm 0.00$ & $\overline{\mathrm{a}}$ & $0.51 \pm 0.10$ & $\overline{a, b}$ \\
\hline WV216A & G. luteum & $0.09 \pm 0.01$ & $\mathrm{a}$ & $1.80 \pm 0.07$ & $\mathrm{n}=4$ & $\mathrm{~b}, \mathrm{c}, \mathrm{d}$ & $0.02 \pm 0.00$ & $a, b$ & $0.61 \pm 0.32$ & $a, b$ \\
\hline WV221 & G. diaphanum & $0.10 \pm 0.01$ & $\mathrm{a}$ & $0.94 \pm 0.01$ & $\mathrm{n}=2$ & $a, b, c$ & $0.03 \pm 0.00$ & $a, b$ & $3.45 \pm 0.71$ & $\mathrm{~b}, \mathrm{~d}$ \\
\hline WV212 & G. brasilianum & $0.19 \pm 0.01$ & $\mathrm{~b}$ & $1.03 \pm 0.05$ & $\mathrm{n}=5$ & $a, b, c$ & $0.05 \pm 0.01$ & $\mathrm{~b}, \mathrm{~d}$ & $2.37 \pm 0.70$ & $\mathrm{~b}$ \\
\hline WV216B & G. eburneum & $0.22 \pm 0.04$ & $\mathrm{~b}, \mathrm{c}$ & $1.93 \pm 0.16$ & $\mathrm{n}=5$ & $\mathrm{~b}, \mathrm{c}, \mathrm{d}$ & $0.03 \pm 0.01$ & $\mathrm{a}, \mathrm{b}, \mathrm{d}$ & $1.59 \pm 0.50$ & $\mathrm{~b}$ \\
\hline WV220 & G. claroideum & $0.25 \pm 0.02$ & $\mathrm{~b}, \mathrm{c}, \mathrm{d}$ & $1.48 \pm 0.11$ & $\mathrm{n}=5$ & $\mathrm{~b}, \mathrm{c}, \mathrm{d}$ & $0.07 \pm 0.01$ & $\mathrm{~b}, \mathrm{c}, \mathrm{d}$ & $2.65 \pm 0.96$ & $\mathrm{~b}$ \\
\hline WV218 & Glomus sp. WV218 & $0.27 \pm 0.01$ & $\mathrm{~b}, \mathrm{c}, \mathrm{d}$ & $1.63 \pm 0.02$ & $\mathrm{n}=5$ & $\mathrm{~b}, \mathrm{c}, \mathrm{d}$ & $0.04 \pm 0.00$ & $\mathrm{~b}, \mathrm{~d}$ & $2.85 \pm 0.41$ & $\mathrm{~b}$ \\
\hline WV219A & G. clarum & $0.30 \pm 0.02$ & $\mathrm{~b}, \mathrm{c}, \mathrm{d}$ & $1.16 \pm 0.04$ & $\mathrm{n}=5$ & $a, b, c$ & $0.06 \pm 0.01$ & $\mathrm{~b}, \mathrm{c}, \mathrm{d}$ & $7.96 \pm 0.96$ & $\mathrm{~b}, \mathrm{c}, \mathrm{d}$ \\
\hline WV230 & G. intraradices & $0.31 \pm 0.04$ & $\mathrm{~b}, \mathrm{c}, \mathrm{d}$ & $1.48 \pm 0.09$ & $\mathrm{n}=5$ & $\mathrm{~b}, \mathrm{c}, \mathrm{d}$ & $0.06 \pm 0.01$ & $\mathrm{~b}, \mathrm{c}, \mathrm{d}$ & $6.08 \pm 0.61$ & $\mathrm{~b}, \mathrm{c}, \mathrm{d}$ \\
\hline WV214B & Glomus sp. WV214B & $0.34 \pm 0.01$ & $\mathrm{~b}, \mathrm{c}, \mathrm{d}$ & $1.24 \pm 0.07$ & $\mathrm{n}=5$ & $\mathrm{a}, \mathrm{b}, \mathrm{c}, \mathrm{d}$ & $0.07 \pm 0.00$ & $\mathrm{~b}, \mathrm{c}, \mathrm{d}$ & $4.15 \pm 0.86$ & $\mathrm{~b}, \mathrm{~d}$ \\
\hline
\end{tabular}




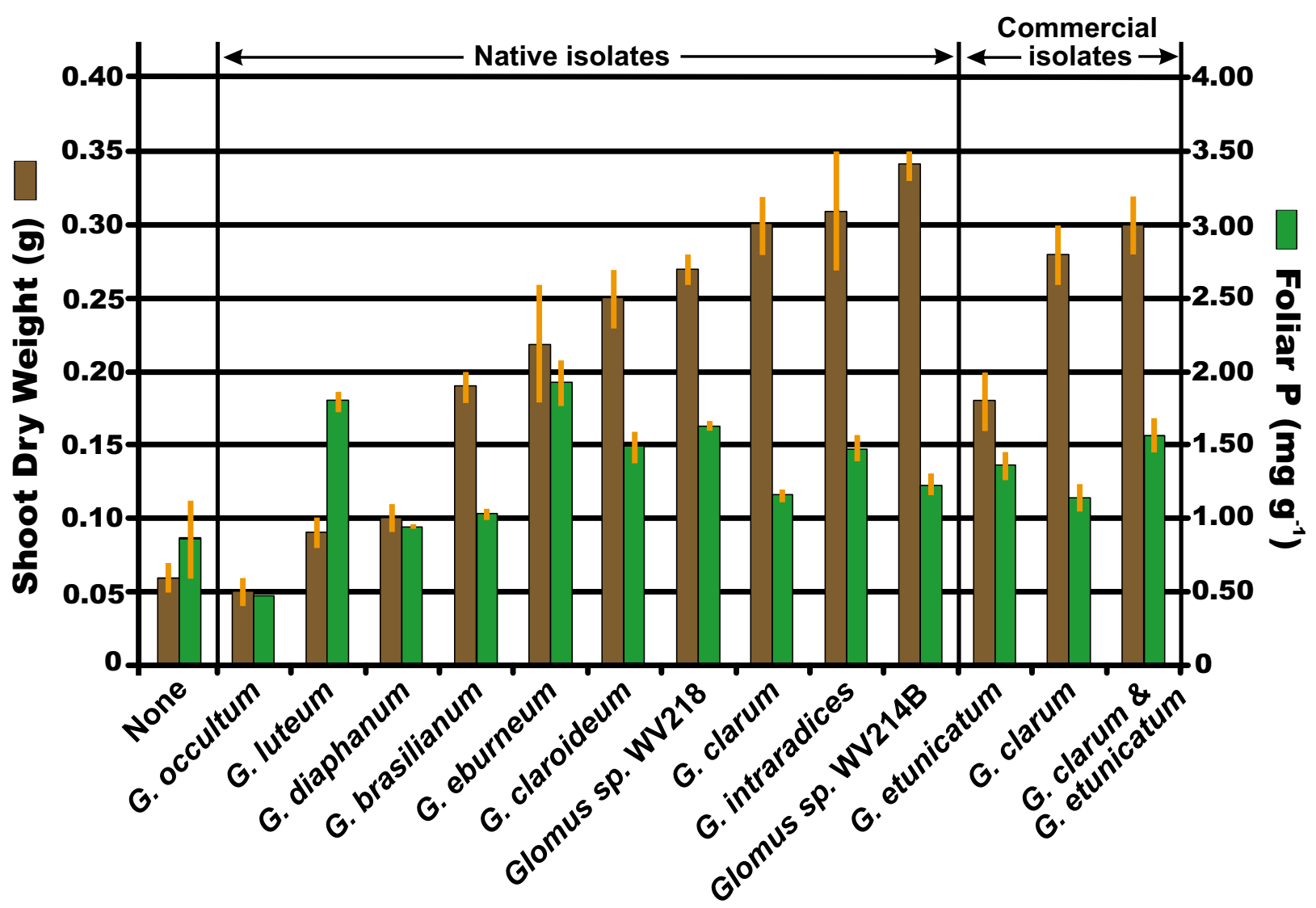

Fungal species

Figure 1. Responses of 7-week-old red clover plants to colonization by ten indigenous isolates from Mingo County plots and commercial isolates. Bars represent standard error. 


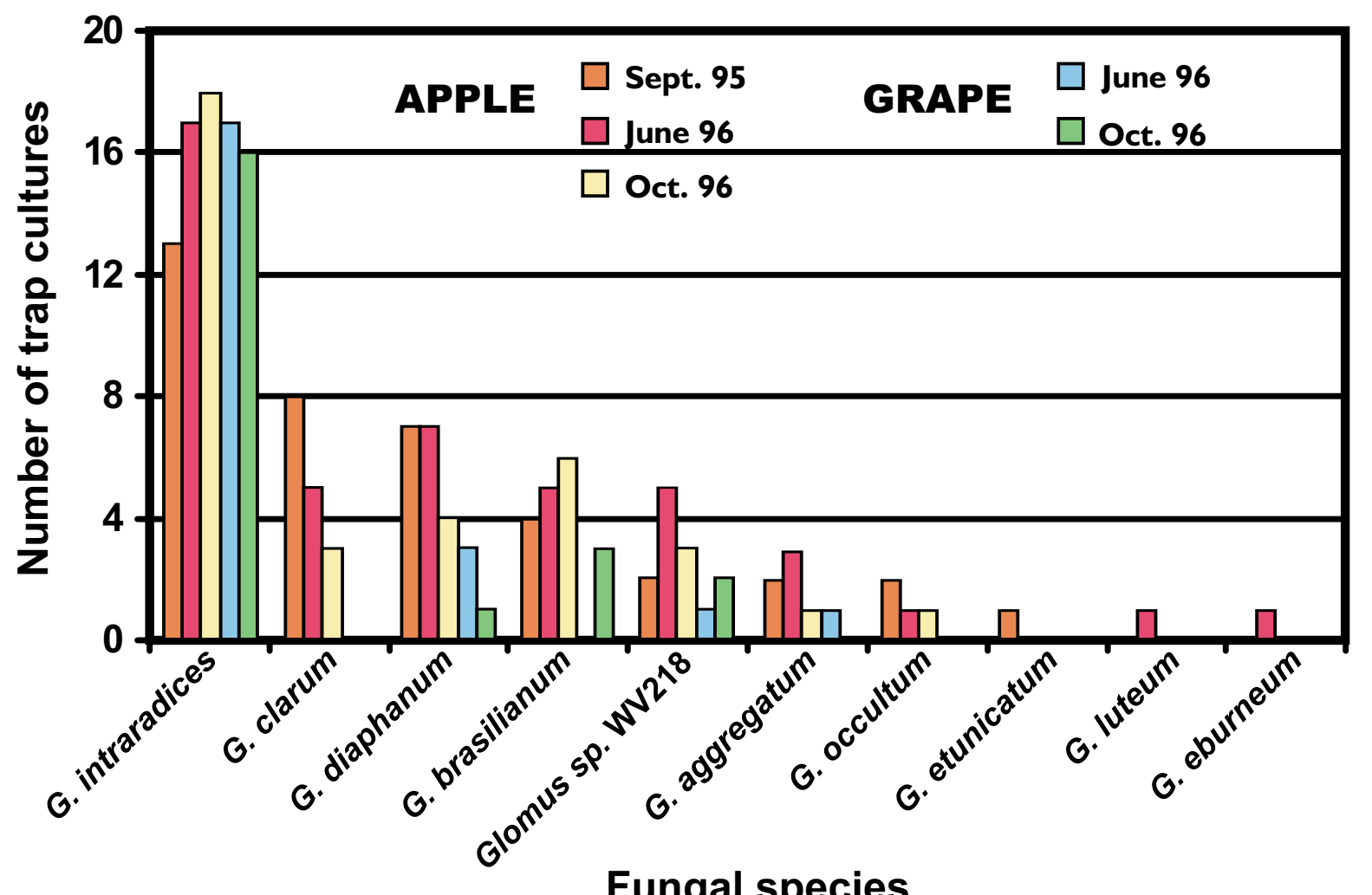

Fungal species

Figure 2. Occurrence of AMF species detected by sporulation in trap cultures of apple and grape roots at several sampling dates. 


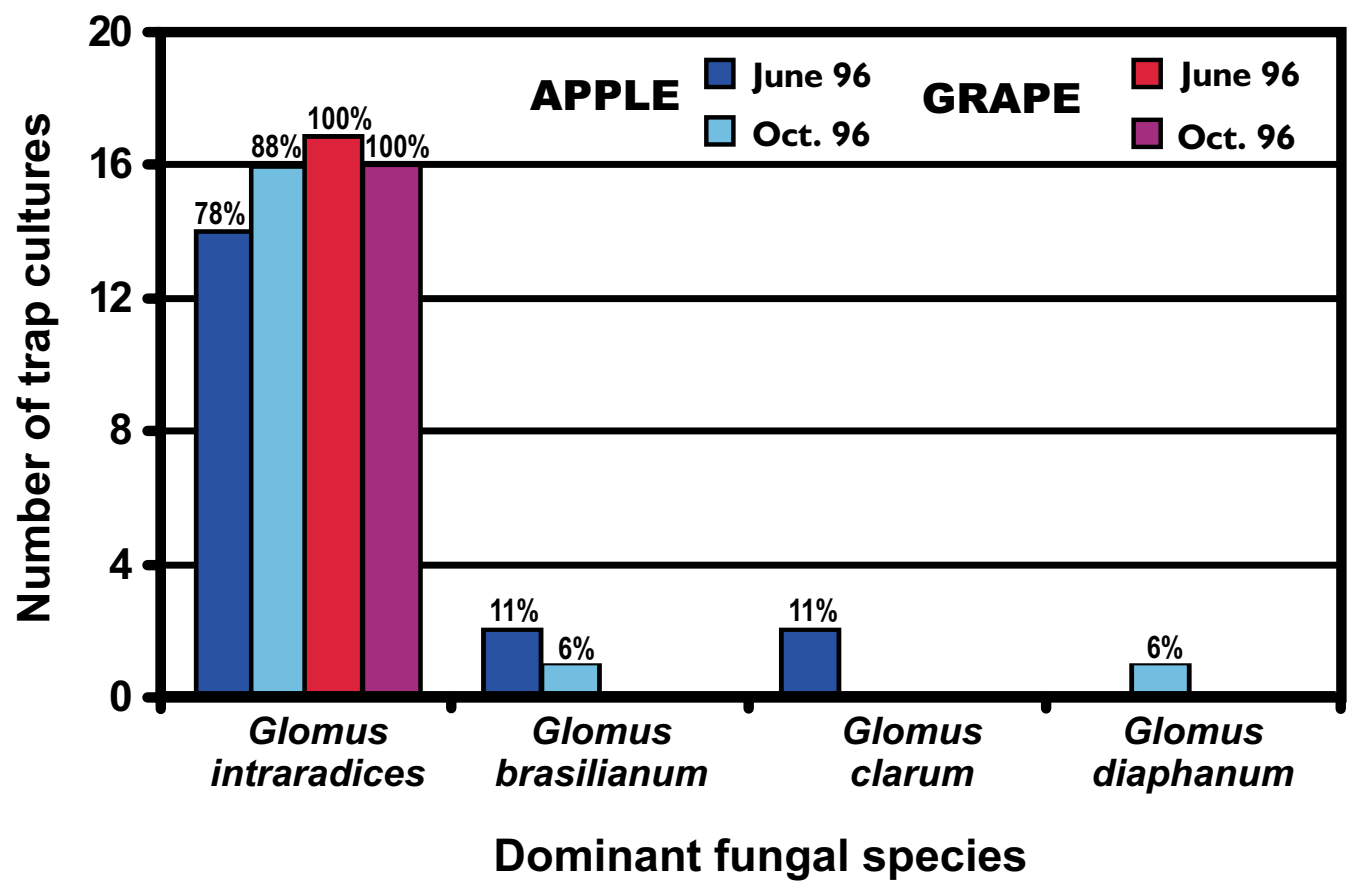

Figure 3. Dominant fungi sporulating in trap pot cultures of apple and grape roots collected on two sampling dates. Percentage of the total number of apple or grape trap cultures dominated by each species on each date are shown above the bars. 


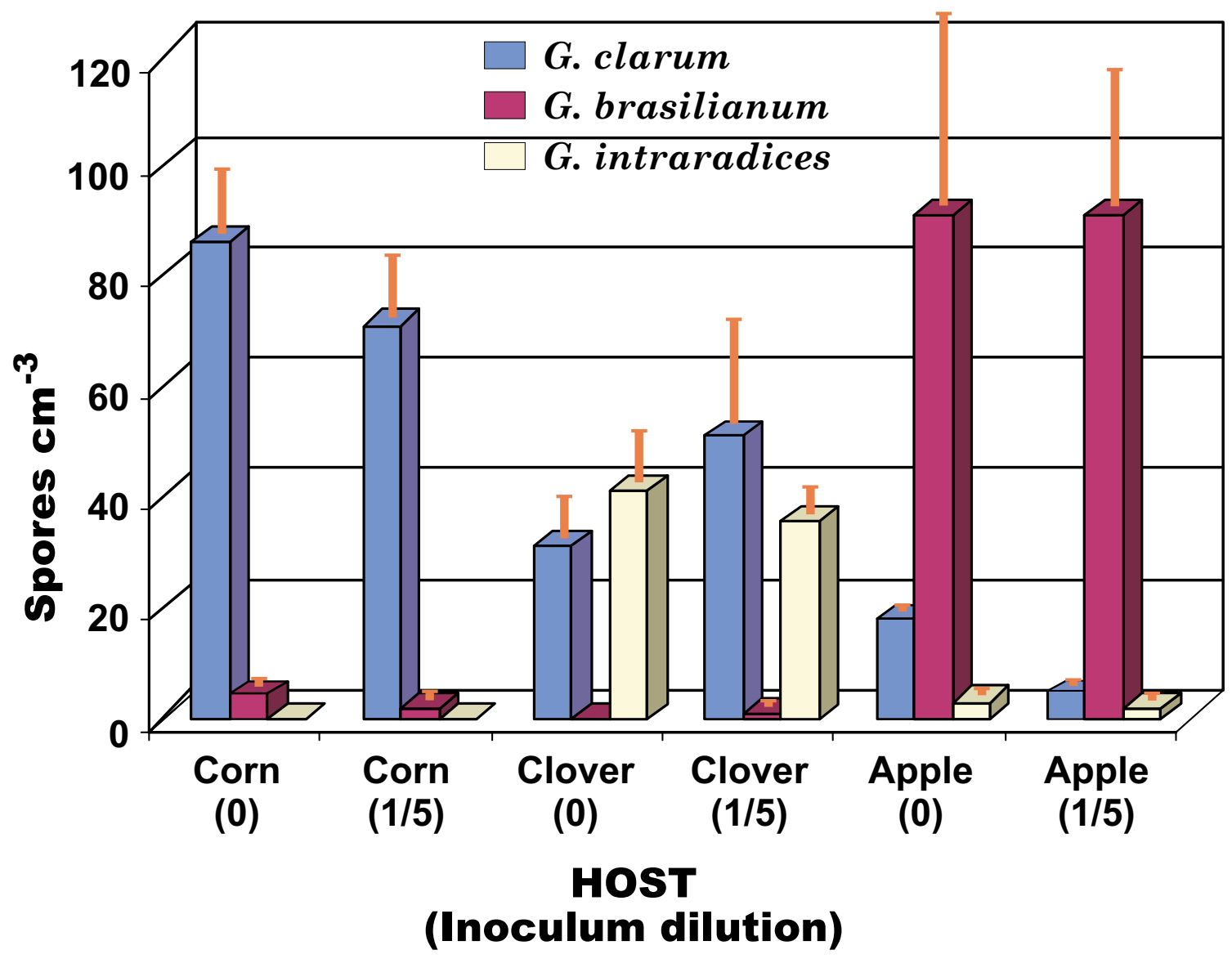

Figure 4. Sporulation by AMF isolates in a mixed inoculum grown on three different host plants at two dilutions. Bars indicate standard error. 


\section{CHAPTER TWO}

\section{THRESHOLD LEVELS OF MYCORRHIZAL COLONIZATION ARE NEEDED FOR SPORULATION BY FUNGAL SPECIES IN GLOMALES}




\section{INTRODUCTION}

Many studies examining species richness of arbuscular mycorrhizal fungi in plant communities are complicated by the inability to detect species that do not sporulate in the field (Bever et al., 1996; Morton et al., 1995). In environments where mycorrhizal colonization is constrained, such as arid and semi-arid habitats, sporulation may be absent or represent only a small fraction of the total number of fungal species colonizing roots (Pond et al., 1984; Stutz and Morton, 1996). The relationship between colonization and sporulation by arbuscular fungi is an important life history trait impacting on the biology and ecology of the mycorrhizal symbiosis. This relationship also is important methodologically in assessing the presence of species in the field or in pot cultures. One aspect of this relationship is the extent to which a minimum level of root colonization by an arbuscular fungus is necessary before sporulation can occur. Threshold levels have been measured in species of Acaulospora (Gazey et al., 1992) and Scutellospora (Pearson and Schweiger, 1993; Franke and Morton, 1994), but little is known about other genera in Glomales. An understanding of the universality of this phenomenon is important for both field and greenhouse studies that rely on sporulation for detection and estimation of relative abundance. In this study, representative species of all families in Glomales were compared in the mycotrophic legume host, Trifolium pratense L. (red clover).

\section{MATERIALS AND METHODS}

\section{Preparation of nurse plants}

Isolates of five species of arbuscular fungi from the International Culture Collection of Arbuscular and Vesicular Arbuscular Mycorrhizal Fungi (INVAM) were used for this study: Acaulospora morrowiae Spain \& Schenck BR983A; Glomus etunicatum Becker \& Gerdemann WV977; Glomus intraradices Schenck \& Smith UT187; Gigaspora gigantea (Nicol. \& Gerd.) Gerdemann \& Trappe MN922A; and, Scutellospora heterogama (Nicol. \& Gerdemann) Walker \& Sanders WV858B. "Whole" inoculum (Morton et al., 1993) of each fungal isolate was mixed 1:10 (v/v) with a low nutrient sand:soil (Lily series, $0.9 \%$ organic matter, pH 5.5, 8.0 $\mu \mathrm{g} / \mathrm{g}$ bicarbonate-extractable phosphorus mixed 1:2 v/v with \#3 Quartzite sand) and placed in 4 x 21-cm Cone-tainers ${ }^{\mathrm{TM}}$ (Stuewe and Sons, Corvallis, OR) seeded with sudangrass plants [Sorghum sudanese (Staph.) Piper]. Plants were grown for four months in a greenhouse, with ambient temperature ranging from $19-30^{\circ} \mathrm{C}$ and $245 \mu \mathrm{mol} \mathrm{m} \mathrm{s}^{-1} \mathrm{PAR}$ for $14 \mathrm{hrs}$ each day.

\section{Potting media}

Experimental potting medium consisted of soil (Lily series, $0.9 \%$ organic matter, $\mathrm{pH}$ 5.5, $8.0 \mu \mathrm{g} / \mathrm{g}$ bicarbonate-extractable phosphorus) passed through a 7-mm sieve, mixed 1:1 (v/v) with sterile \#3 quartzite sand (Penn Glass Company, Berkeley Springs, WV), steamsterilized at $100^{\circ} \mathrm{C}$ for one hour on two consecutive days, and air-dried. To regulate levels of mycorrhizal colonization, three $\mathrm{P}$ concentrations were prepared: 0,150 , and $450 \mathrm{mg} \mathrm{kg}^{-1}$ added $\mathrm{P}\left(\right.$ as $\left.\mathrm{KH}_{2} \mathrm{PO}_{4}\right) . \mathrm{KCl}$ was added to 0 and $150 \mathrm{mg} \mathrm{kg}^{-1} \mathrm{P}$ treatments to equalize potassium concentrations. $\mathrm{CaCO}_{3}$ (to $\mathrm{pH}$ 6.6) and $\mathrm{KH}_{2} \mathrm{PO}_{4}$ and/or $\mathrm{KCl}$ for the various treatments were added to Modified Hoagland's Solution (Millner and Kitt, 1992) further modified by the 
omission of $\mathrm{KH}_{2} \mathrm{PO}_{4}, \mathrm{MnCl}_{2} \bullet 4 \mathrm{H}_{2} \mathrm{O}, \mathrm{HCl}$, and MES buffer, and the substitution of $\mathrm{NH}_{4} \mathrm{NO}_{3}$ for $\mathrm{KNO}_{3}$. This fertilizer was added at a rate of $1 \mathrm{ml} \mathrm{kg}^{-1}$ of potting medium. The potting medium was dried for one week, then rewetted. A bacterial suspension from unsterilized Lily soil was prepared by placing $1000 \mathrm{~cm}^{3}$ soil in $4 \mathrm{~L}$ tap water, incubating overnight at room temperature, and sieving to $<15 \mu \mathrm{m}$. This solution was added to the potting medium at a rate of $35 \mathrm{ml}$ solution $\mathrm{kg}$ soil $^{-1}$. To verify that the potting medium was sterile, samples from each $\mathrm{P}$ treatment were added to three cone-tainers. Each cone-tainer was seeded with red clover (variety Kenland), and inoculated with $25 \mathrm{ml}$ of a Rhizobium trifolii (LiphaTec, Inc., Milwaukee, Wisconsin) suspension consisting of $50 \mathrm{~cm}^{3}$ of commercial mix per $\mathrm{L} \mathrm{ddH}_{2} \mathrm{O}$.

\section{Experimental set-up}

Sudangrass plants with attached soil were gently removed from cone-tainers (see above) and transplanted into sleeves of Nitex nylon mesh with 140- $\mu$ m openings (Tetko, Inc., Briar Cliff Manor, NY). The sleeves were positioned in the center of $15 \mathrm{~cm}$-diam plastic pots and surrounded with potting medium. Each fungus-phosphorus treatment was replicated in four pots. The potting medium surrounding the mesh sleeve in each pot was seeded with approximately 200 seeds of red clover (Fig. 1). At seedling emergence, a suspension of Rhizobium trifolii (see above) was added at a rate of $85 \mathrm{ml}$ per pot or $25 \mathrm{ml}$ per control conetainer. Pots were arranged in a randomized complete block design and were grown under controlled light $\left(195 \mu \mathrm{mol} \mathrm{m} \mathrm{m}^{-2} \mathrm{PAR} ; 16 \mathrm{hr}\right.$ daylength) and temperature $\left(21-28{ }^{\circ} \mathrm{C}\right)$ conditions. Nitrogen fertilizer was added once midway through the experiment.

\section{Sampling strategy}

A 2- to 3-cm wide section of potting medium outside the mesh sleeve was cut from each pot at 21-day intervals after the first sampling date (4 wk after plant emergence), for a total of four sampling dates. Two to three plants were gently separated and roots were washed and excised. A subsample was cleared for 5 minutes in $10 \% \mathrm{KOH}$ heated to boiling, acidified for 5 minutes in $2 \% \mathrm{HCl}$, and stained for 3 minutes in $0.5 \%$ Direct Blue heated to boiling (modified from Phillips and Hayman, 1970). Percentage mycorrhizal colonization was measured by the grid-line intercept method (Giovannetti and Mosse, 1980). Spores were extracted from a $50-\mathrm{cm}^{3}$ sample of soil from each pot sample by wet-sieving (38- and $500-\mu \mathrm{m}$ sieves) followed by centrifugation at $900 \mathrm{x}$ g in 20/60\% sucrose gradients (Daniels and Skipper, 1982). Spores suspended in the supernatant were decanted, washed thoroughly, transferred to a plastic Petri dish, then enumerated under a stereomicroscope.

\section{Statistical analyses}

A variety of regressions were performed on the colonization and sporulation data, with the aid of Microsoft ${ }^{\circledR}$ Excel. Gompertz equations were fitted with the aid of SAS (SAS Institute). Correlation coefficient $\left(r^{2}\right)$ values of relationships for each species were calculated. 


\section{RESULTS}

Colonization and sporulation decreased in direct proportion to the amount of $\mathrm{P}$ added to the potting medium (results not shown). No colonization or sporulation were detected in nonmycorrhizal controls. Mycorrhizal development in pots amended with $450 \mathrm{mg} \mathrm{kg}^{-1} \mathrm{P}$ was reduced to $<9 \%$ with minimal sporulation, so they were excluded from the data set. Only pots with no added $\mathrm{P}$ and $150 \mathrm{mg} \mathrm{kg}^{-1}$ added $\mathrm{P}$ were used to determine relationships between colonization and sporulation.

Colonization and sporulation were highly correlated. The best fit for this relationship was a Gompertz equation, with $\mathrm{r}^{2}$ values ranging from 0.49 (G. etunicatum) to 0.96 ( $S$. heterogama) (Figs. 2-6). In pots amended with $150 \mathrm{mg} \mathrm{kg}^{-1} \mathrm{P}$, mycorrhizal colonization did not exceed $23 \%$.

In some pots, limited sporulation occurred at very low levels of mycorrhizal colonization. Gompertz plots (Figs. 2-6) were used to identify the threshold level of mycorrhizal colonization at which sporulation was initiated for all species examined (Table 1). The onset of sporulation occurred between 10\% (Glomus etunicatum) and 30\% colonization (Gi. gigantea and S. heterogama).

\section{DISCUSSION}

Threshold levels of colonization have been measured in species of Glomaceae (G. etunicatum and G. intraradices, this study), Acaulosporaceae (A. laevis and Acaulospora sp. WUM18, Gazey et al., 1992; A. morrowiae, this study), and Gigasporaceae (Gi. gigantea, this study; S. calospora, Pearson and Schweiger, 1993; S. pellucida, Franke and Morton, 1994; and, S. heterogama, Franke and Morton, 1994, this study). Collectively, therefore, we conclude that all species of arbuscular mycorrhizal fungi in Glomales require some level of colonization before sporulation is initiated.

All relationships between colonization and sporulation require multiple sampling over time (Gazey et al., 1992; Franke and Morton, 1994; Pearson and Schweiger, 1993).

Controlling the rate and amount of mycorrhizal development among different fungal genotypes can be accomplished either by varying inoculum density (Gazey et al., 1992) or modifying P levels in the potting medium (this study). Each method involves different considerations. Changes in inoculum density affect only fungus-related variables that impact on initial infectivity. Increasing P levels, in contrast, impacts on a more complex sets of variables associated with both the host and the fungus. Fungal colonization may be inhibited directly by decreases in root exudates affecting initial colonization (Ratnayake et al., 1978; Graham, 1981) or by decreases in amounts of soluble carbohydrates translocated to the roots affecting colonization at all stages of development (Jasper et al., 1979). Alternatively, fungal colonization may not be inhibited at all, but only appear to decrease because of a dramatic increase in rate of host root growth with no change in the rate of fungal growth (Buwalda et al., 1982). Thus, the effects of $P$ addition on unmeasured host variables, such as rate and amount of root development, may impact significantly on interpretation of the relationship between colonization and sporulation. 
Sporulation at colonization levels below the threshold predicted by Gompertz plots occurred only in pots amended with $150 \mathrm{mg} \mathrm{kg}^{-1} \mathrm{P}$. With increased $\mathrm{P}$ fertility, red clover shoot and root biomass also increased (results not shown). Percentage colonization measurements likely underestimated the amount of fungal biomass present relative to total root length, so that Gompertz plots may be underestimating colonization levels at which spores are first formed. Measurement of colonization by mycorrhizal root length would not have provided additional useful information, since it also would have been based on a finite root sample.

All studies examining threshold levels of colonization have employed highly mycotrophic hosts. The legumes used in all studies thus far, Trifolium subterraneum L. cv. Seaton Park (Gazey et al, 1992; Pearson and Schweiger, 1993) or Trifolium pratense (Franke and Morton, 1994; this study), depend on the mycorrhizal association because of a high phosphorus requirement for dinitrogen fixation (Barea and Azcon-Aguilar, 1983; Morton et al., 1990). Franke and Morton (1993) found similar thresholds of colonization in both Sorghum sudanese (Piper) Staph. (sudangrass) and red clover, suggesting that fungal biomass needed for sporulation may be independent of host species. A true test of this hypothesis, however, would require comparisons with less mycotrophic grasses or other host species that have much lower colonization maxima.

Pot design also contributed to some sporulation not directly attributable to mycorrhizal colonization in red clover. Some fine roots from sudangrass grew outside the mesh sleeve because of the mesh opening size $(140 \mu \mathrm{m})$, and in a few pots, roots grew over the top of the mesh sleeve. These roots, if mycorrhizal, would have produced a low level background of spores most evident in treatments with little or no sporulation. Thus, the threshold levels reported here are minimum estimates and may actually be higher under different experimental conditions.

Despite the limitations of this study, the Gompertz plots clearly indicate that threshold levels of colonization for sporulation are operational. Similar threshold levels of colonization (Table 1) among some of the species tested (e.g., G. intraradices, Gi. gigantea, and $S$.

heterogama) suggests that sporulation is less a function of unique life history traits than it is the amount of fungal biomass produced by those species in mycorrhizae.

Substantive threshold levels of mycorrhizal colonization for sporulation have broad implications for analysis of species diversity based on sporulation in field or greenhouse soils. In field studies, multiple samplings are needed to capture spores when colonization is likely to be optimal or when differential colonization and sporulation is occurring with changing environmental conditions (Bever et al., 1996). Habitats in which mycorrhizal colonization tends to be low (e.g., arid conditions) require greenhouse baiting methods to increase fungal biomass sufficiently to stimulate sporulation (e.g., Stutz and Morton, 1996; Stutz et al., 2000).

Threshold levels of colonization also have implications for the culture of arbuscular mycorrhizal fungi. In successive culturing of a given fungal isolate, "contaminant" arbuscular fungi sometimes appear even when extreme measures have been taken to prevent pot-to-pot spread (Morton, unpubl.). In many cases, these contaminants can be traced to fungal species present in the original sample (trap culture or field soil sample). Some species may coexist 
throughout subculturing regimens only as mycorrhizae, so that cultures appear monospecific based on sporulating patterns. These cryptic species then would appear only when

environmental changes cause enough of an increase in fungal biomass for sporulation to occur.

The impact of threshold levels of colonization on behavior of fungal organisms in complex communities (see Chapter 1) is unclear. Each fungus in a mycorrhiza may behave independent of all others present, as suggested by stochastic taxonomic diversity (Morton, unpubl.), or fungal symbionts may interact directly or indirectly as carbon sinks (Graham et al., 1997). Answers will come only with the application of molecular probes that may be used to quantify directly the amount of colonization by individual fungi in a mycorrhizal community. 


\section{REFERENCES}

Barea, J. M. and C. Azcon-Aguilar. 1983. Mycorrhizae and their significance in nodulating $\mathrm{N}$-fixing plants. Advances in Agronomy 36:1-54.

Bever, J. D., J. B. Morton, J. Antonovics, and P. A. Schultz. 1996. Host-dependent sporulation and species diversity of arbuscular mycorrhizal fungi in a mown grassland. Journal of Ecology 84:71-82.

Buwalda, J. G., G. J. S. Ross, D. P Stribley, and P. B. Tinker. 1982. The development of endomycorrhizal root systems. IV. The mathematical analysis of effects of phosphorus on the spread of vesicular-arbuscular mycorrhizal infection in root systems. New Phytologist 92:391-399.

Daniels, B. A., and H. D. Skipper. 1982. Methods for the recovery and quantitative estimation of propagules from soil. In: Methods and principles of mycorrhizal research, N.C. Schenck, ed. pp. 29-35. APS Press, St. Paul, Minnesota.

Franke, M. and J. Morton. 1994. Ontogenetic comparisons of arbuscular mycorrhizal fungi Scutellospora heterogama and Scutellospora pellucida: revision of taxonomic character concepts, species descriptions, and phylogenetic hypotheses. Canadian Journal of Botany 72:122-134.

Gazey, C., L. K. Abbott, and A. D. Robson. 1992. The rate of development of mycorrhizas affects the onset of sporulation and production of external hyphae by two species of Acaulospora. Mycological Research 96:643-650.

Giovannetti, M., and B. Mosse. 1980. An evaluation of techniques for measuring vesicular arbuscular mycorrhizal infection in roots. New Phytologist 84: 489-500.

Graham, J. H., R. T. Leonard, and J. A. Menge. 1981. Membrane-mediated decrease in root exudation responsible for phosphorus inhibition of vesicular-arbuscular mycorrhiza formation. Plant Physiology 68:548-552.

Graham, J. H., L. W. Duncan, and D. M. Eissenstat. 1997. Carbohydrate allocation patterns in citrus genotypes as affected by phosphorus nutrition, mycorrhizal colonization, and mycorrhizal dependency. New Phytologist 135:335-343.

Jasper, D. A., A. D. Robson, and L. K. Abbott. 1979. Phosphorus and the formation of vesicular-arbuscular mycorrhizas. Soil Biology and Biochemistry 11:501-505.

Millner, P. D., and D. G. Kitt. 1992. The Beltsville method for soilless production of vesiculararbuscular mycorrhizal fungi. Mycorrhiza 2:9-15. 
Morton, J. B. 1999. Evolution of endophytism in arbuscular mycorrhizal fungi of Glomales. In: Microbial Endophytes, C. W. Bacon and J. F. White, eds. pp. 121-140. Marcel Dekker, Inc., New York.

Morton, J. B., S. P. Bentivenga, and J. D. Bever. 1995. Discovery, measurement, and interpretation of diversity in arbuscular endomycorrhizal fungi (Glomales, Zygomycetes). Canadian Journal of Botany 73:S25-S32.

Morton, J. B., J. E. Yarger, and S. F. Wright. 1990. Soil solution P concentrations necessary for nodulation and nitrogen fixation in mycorrhizal and non-mycorrhizal red clover (Trifolium pratense L.). Soil Biology and Biochemistry 22:127-129.

Pearson, J. N. and P. Schweiger. 1993. Scutellospora calospora (Nicol. \& Gerd.) Walker \& Sanders associated with subterranean clover: dynamics of colonization, sporulation and soluble carbohydrates. New Phytologist 124:215-219.

Phillips, J. M., and D. S. Hayman. 1970. Improved procedures for clearing roots and staining parasitic and vesicular-arbuscular mycorrhizal fungi for rapid assessment of infection. Transactions of the British Mycological Society 55:158-161.

Pond, E. C., J. A. Menge, and W. M. Jarrell. 1984. Improved growth of tomato in salinized soil by vesicular-arbuscular mycorrhizal fungi collected from saline soils. Mycologia 76:7484.

Ratanayake, M., R. T. Leonard, and J. A. Menge. 1978. Root exudation in relation to supply of phosphorus and its possible relevance to mycorrhiza formation. New Phytologist 81:544-552.

Stutz, J. and J. B. Morton. 1996. Successive pot cultures reveal high species richness of indigenous arbuscular endomycorrhizal fungi in arid ecosystems. Canadian Journal of Botany 74:1883-1889.

Stutz, J. C., R. Copeman, C. A. Martin, and J. B. Morton. 2000. Patterns of species composition and distribution of arbuscular mycorrhizal fungi in arid regions of southwestern North America and Namibia, Africa. Canadian Journal of Botany (in press). 


\begin{tabular}{|l|c|}
\hline \multicolumn{1}{|c|}{ FUNGAL SPECIES } & $\begin{array}{c}\text { COLONZATION } \\
\text { THRESHOLD }\end{array}$ \\
\hline A. morrowiae & $16 \%$ \\
G. etunicatum & $10 \%$ \\
G. intraradices & $25 \%$ \\
Gi. gigantea & $30 \%$ \\
S. heterogama & $30 \%$ \\
\hline
\end{tabular}

Table 1. Summary of predicted threshold levels of colonization based on Gompertz regressions. 


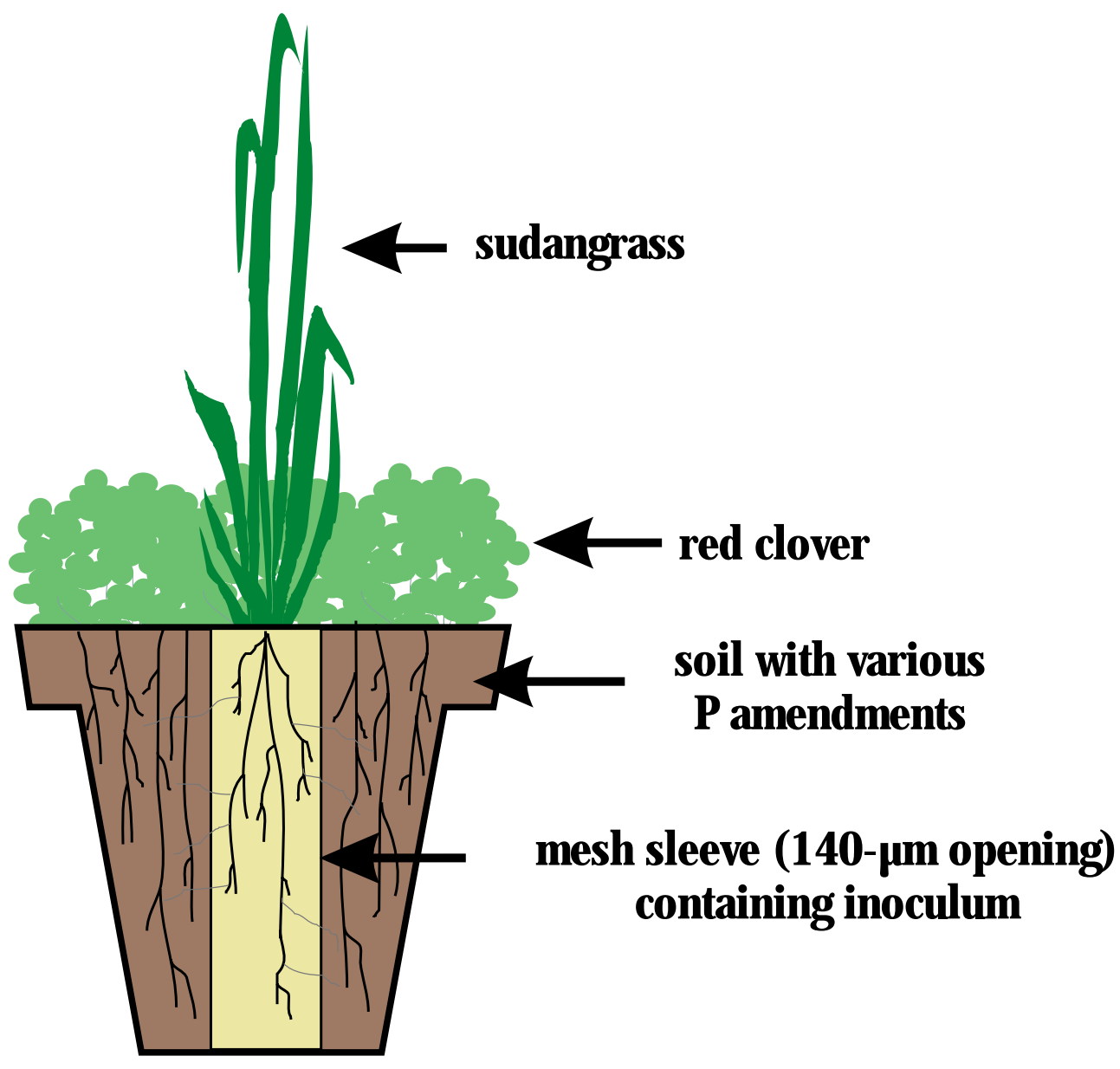

Figure 1. Intact mycorrhizal plants, with roots and associated soil encased by a nylon mesh sleeve with 140- m openings, were transplanted into the centers of $15 \mathrm{~cm}$-diameter $\left(1200 \mathrm{~cm}^{3}\right)$ pots, and surrounded by soil with 0,150 , or $450 \mathrm{mg} \mathrm{kg}^{-1}$ added $\mathrm{P}\left(\right.$ as $\mathrm{KH}_{2} \mathrm{PO}_{4}$ ). 


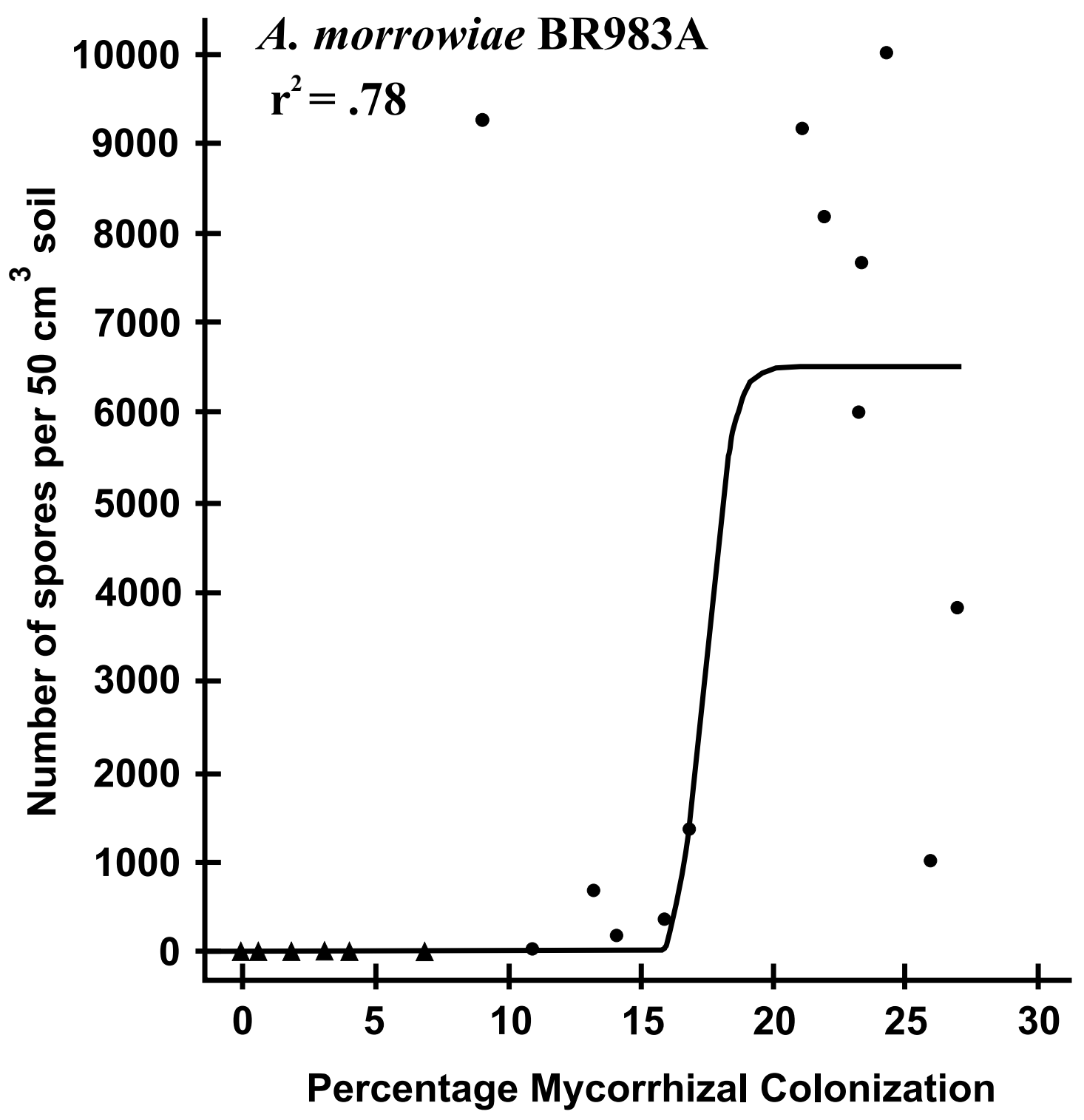

Figure 2. Relationship between percentage mycorrhizal colonization and sporulation by $A$. morrowiae BR983A in red clover grown at two $\mathrm{P}$ concentrations: $\bullet, 0$ added $\mathrm{P} ; \boldsymbol{\Lambda}, 150 \mathrm{mg} \mathrm{kg}^{-1}$ added $\mathrm{P}\left(\right.$ as $\left.\mathrm{KH}_{2} \mathrm{PO}_{4}\right)$. 


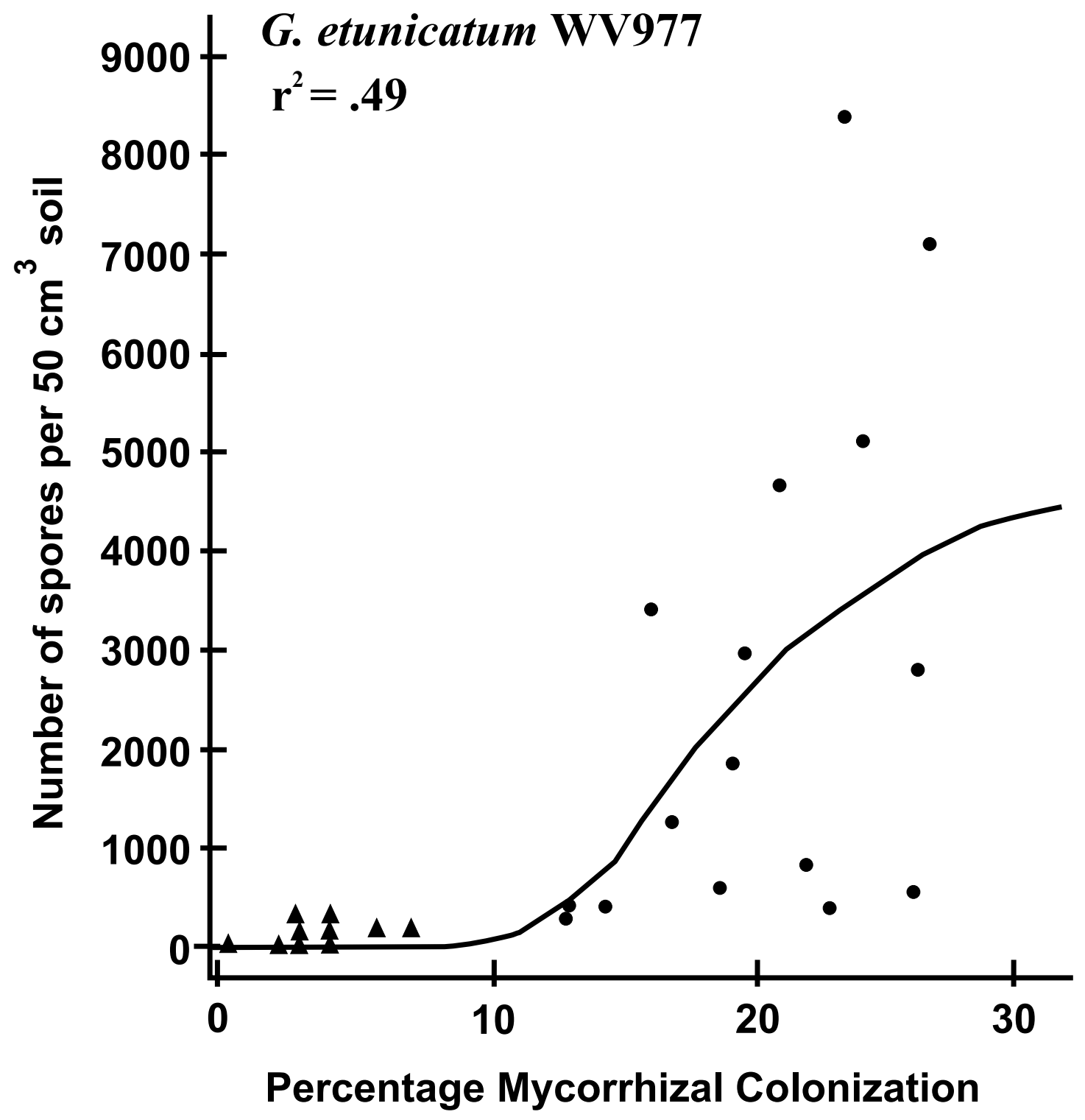

Figure 3. Relationship between percentage mycorrhizal colonization and sporulation by $G$. etunicatum WV977 in red clover grown at two P concentrations: $\bullet, 0$ added $\mathrm{P} ; \boldsymbol{\Lambda}, 150 \mathrm{mg} \mathrm{kg}^{-1}$ added $\mathrm{P}$ (as $\mathrm{KH}_{2} \mathrm{PO}_{4}$ ). 


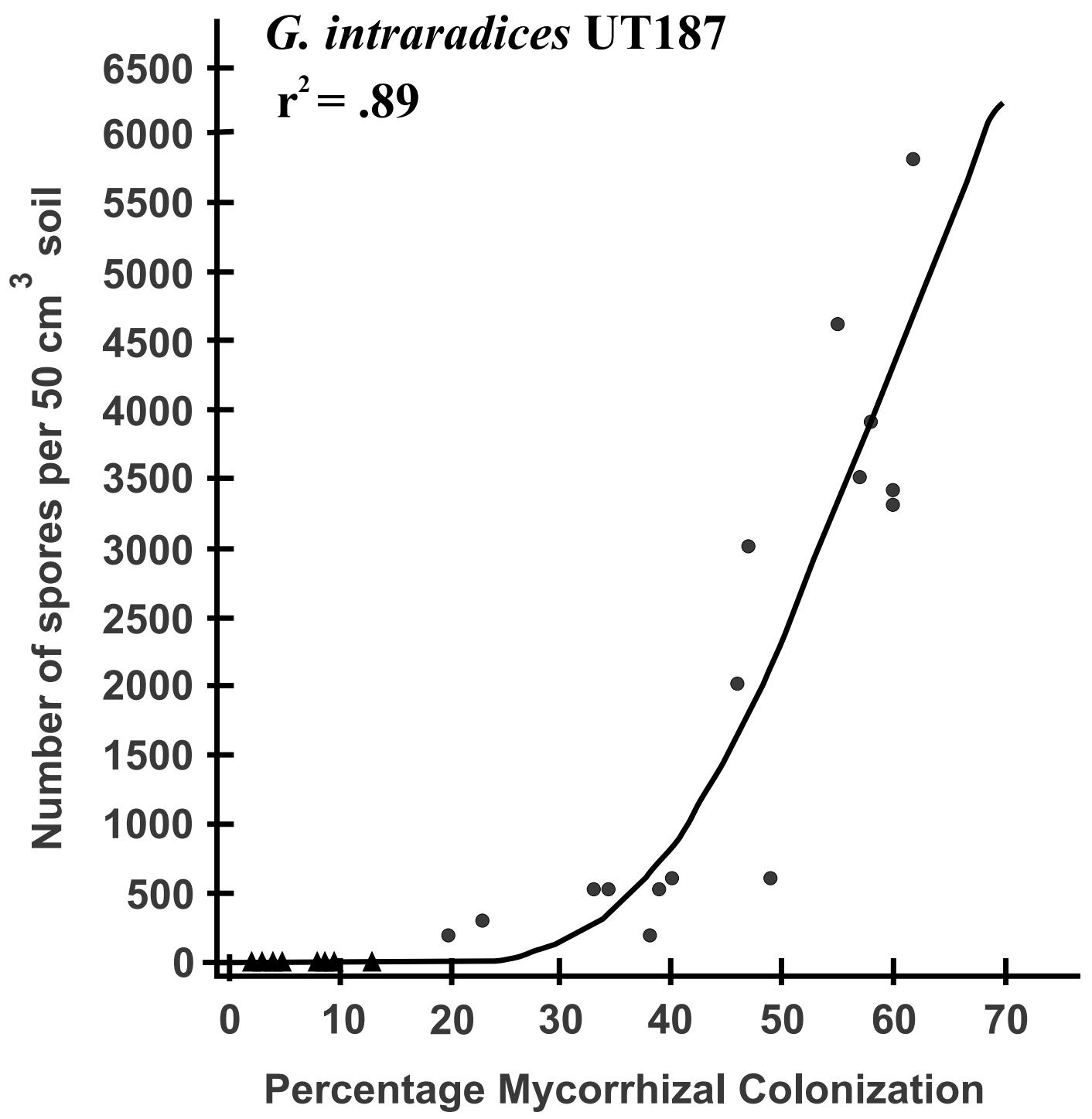

Figure 4. Relationship between percentage mycorrhizal colonization and sporulation by $G$. intraradices UT187 in red clover grown at two P concentrations: $\bullet, 0$ added $\mathrm{P} ; \boldsymbol{\Lambda}, 150 \mathrm{mg} \mathrm{kg}^{-1}$ added $\mathrm{P}$ (as $\mathrm{KH}_{2} \mathrm{PO}_{4}$ ). 


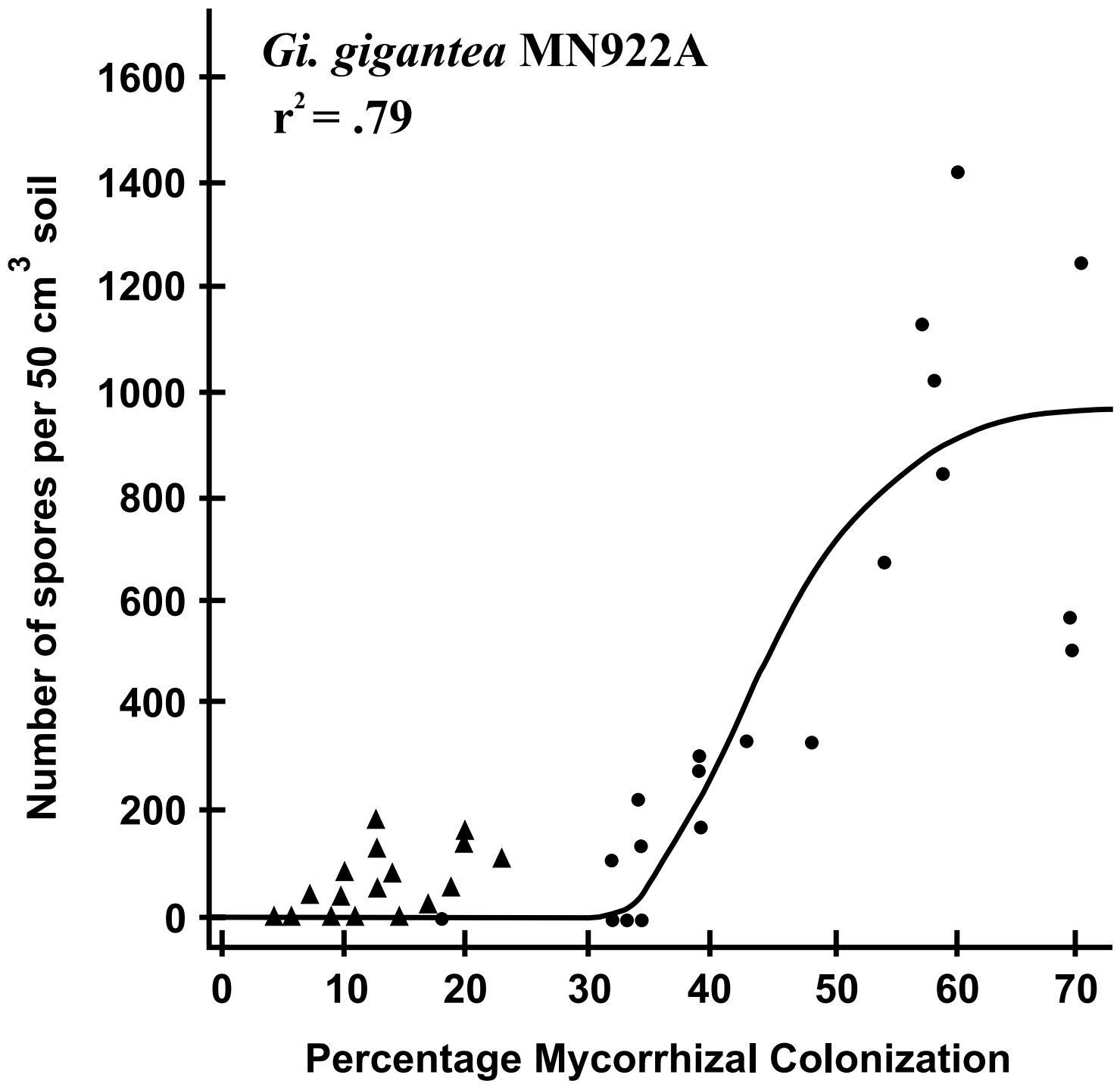

Figure 5. Relationship between percentage mycorrhizal colonization and sporulation by Gi. gigantea MN922A in red clover grown at two P concentrations: $\bullet, 0$ added $\mathrm{P} ; \boldsymbol{\Lambda}, 150 \mathrm{mg} \mathrm{kg}^{-1}$ added $\mathrm{P}\left(\right.$ as $\left.\mathrm{KH}_{2} \mathrm{PO}_{4}\right)$. 


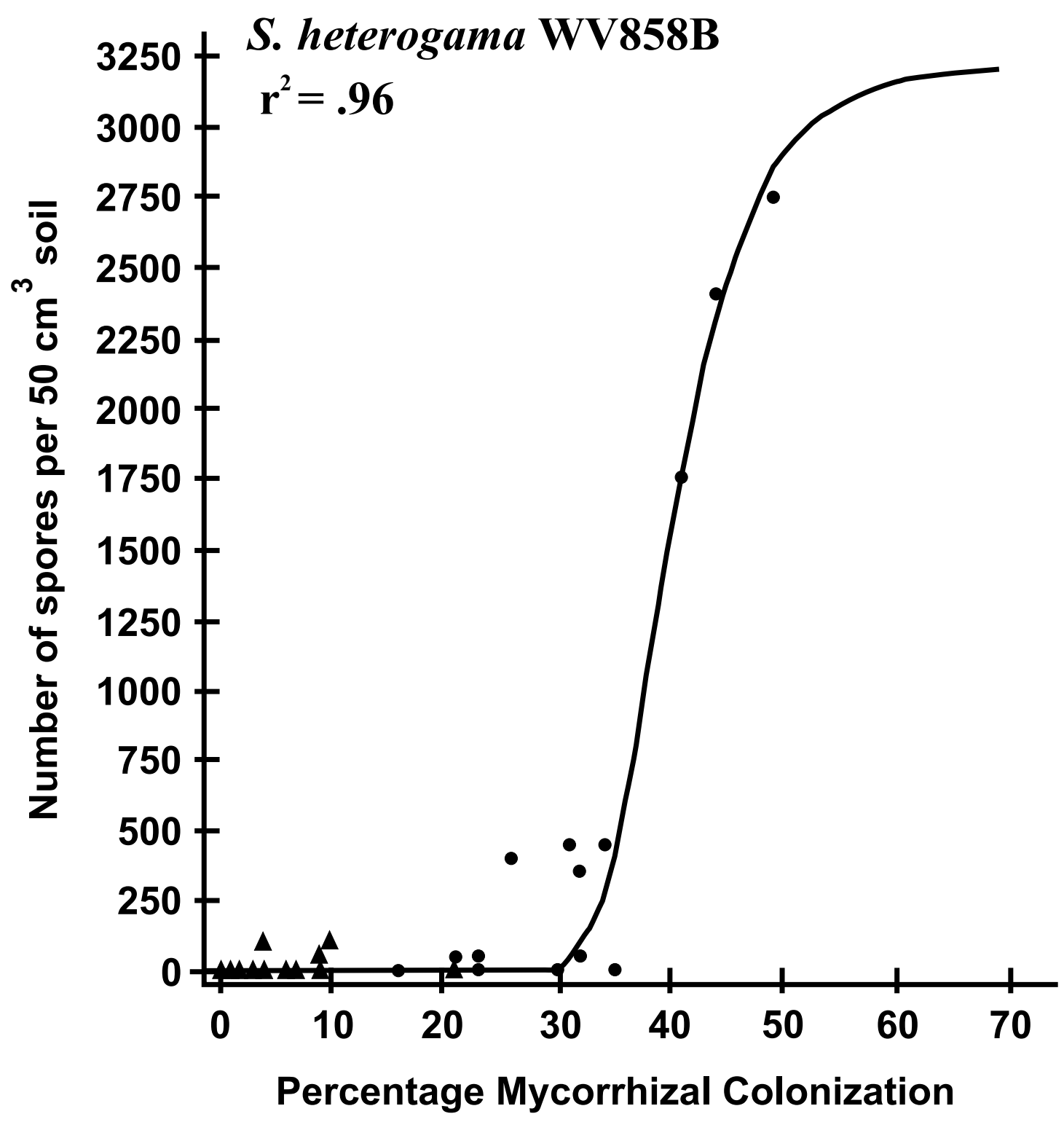

Figure 6. Relationship between percentage mycorrhizal colonization and sporulation by $S$. heterogama WV858B in red clover grown at two P concentrations: $\bullet, 0$ added $\mathrm{P} ; \boldsymbol{\Lambda}, 150 \mathrm{mg} \mathrm{kg}^{-1}$ added $\mathrm{P}$ (as $\mathrm{KH}_{2} \mathrm{PO}_{4}$ ). 


\section{CONCLUSIONS}

Despite increasing knowledge of taxonomic diversity of arbuscular mycorrhizal fungi (AMF) in plant communities, little is known about their functional diversity. With a focus on a revegetated coal strip mine site with a heterogeneous plant community, ten of 14 species of AMF detected were baited and propagated individually in greenhouse pot cultures. Infectivity of fungal inocula was equalized in steamed soil from the site, and relative effectiveness of each fungus was tested on red clover relative to a non-mycorrhizal negative control and inocula of two commercial AMF isolates as positive controls. Three native fungi did not differ significantly from the negative control, and seven were as effective as one or both of the positive controls. Fungal colonization of apple and grape varieties transplanted into the field site was $83-99 \%$ by the end of the second growing season. Eight of these ten native fungi sporulated in trap cultures of apple and grape roots collected at three sampling dates over two growing seasons. For all sampling dates, Glomus intraradices sporulated most abundantly in over $78 \%$ of the apple and in $100 \%$ of the grape root trap cultures. Glomus brasilianum, $G$. clarum, and $G$. diaphanum sporulated most abundantly in the remaining apple traps. Three of these four fungal species ( $G$. intraradices, $G$. brasilianum, and $G$. clarum) were as effective as one or both of the positive controls in benefiting growth of the red clover assay host. Apple seedlings, corn, and red clover grown in the greenhouse for three months with a mixture of these and two other native fungal genotypes at equalized infectivities appeared to be selectively colonized, with $G$. clarum, G. intraradices, and $G$. brasilianum sporulating. These results indicate that $70 \%$ of the isolated fungal species in a native fungal community were as effective at growth promotion as commercial isolates, and that the majority of the fungi colonizing apple and grape roots in the field also were effective symbionts.

Detection and identification of AMF species coexisting in complex communities currently depends on production of soil-borne reproductive spores. However, all colonizing fungal species may not sporulate in natural plant communities, especially in arid habitats. These cryptic species often become apparent in greenhouse trap pot cultures. Such differential behavior raises the question of whether a minimum threshold level of mycorrhizal colonization is needed to induce sporulation. In this study, the relationship between colonization levels in red clover and induction of sporulation were compared among selected isolates of Acaulospora morrowiae, Glomus etunicatum, $G$. intraradices, Gigaspora gigantea, and Scutellospora heterogama. Fungal inoculum consisted of mycorrhizal roots and hyphae from sudangrass nurse plants confined by a nylon mesh barrier in the center of $15-\mathrm{cm}$ diam pots. Colonization levels were environmentally controlled by three soil phosphorus levels. Mycorrhizal colonization and spore density of all fungi were measured on four sampling dates. A Gompertz regression curve provided the best fit for the data, with $\mathrm{r}^{2}$ values ranging from 0.49 ( $G$. etunicatum) to 0.96 (S. heterogama). Threshold levels of mycorrhizal colonization varied considerably among species, ranging from a minimum of $10 \%$ (G. etunicatum) to a maximum of $30 \%$ (Gi. gigantea, S. heterogama). These results corroborate threshold levels determined for other species, further indicating that substantive niche occupation by AMF is needed before sporulation occurs. 


\section{Kelly (Heldreth) Fleming}

313 Grand St., Apt. 1

Morgantown, WV, 26501

Home: (304) 296-1606

Office: (304) 293-3911

Email:kflemin3@wvu.edu

\section{EDUCATION}

M.S. Environmental Microbiology, West Virginia University. 1994 - present.

B.S. Environmental Protection, Plant and Soil Science, West Virginia University. Graduated summa cum laude. 1990 - 1994.

\section{WORK EXPERIENCE}

August 1997 - present. Research Assistant I for Drs. Alan Sexstone and Gary Bissonnette. Duties include: (1) performing a wide variety of physical, chemical, or biological experiments; (2) ordering supplies, materials, and equipment; and, (3) supervising, training, and reviewing the work of students.

August 1994 - present. Graduate research assistant, Dr. Joseph Morton advisor.

Responsibilities entail a research project with the following goals: (1) to isolate and establish in pure plant cultures all of the native arbuscular mycorrhizal fungi present in established plants on a recently reclaimed coal strip mine site in southern West Virginia; (2) to characterize functional diversity and life history properties of cultured fungi; and, (3) to monitor fungal dynamics in roots of apple and grape varieties planted in one-acre experimental plots on this site.

May 1994 - August 1994. Laboratory assistant for Dr. Joseph Morton in the INVAM laboratory. Duties involved assistance in development and maintenance of an international culture collection of arbuscular fungi and organization and input of data into collection databases.

January 1993 - April 1993 and August 1993 - July 1994. Laboratory assistant for Dr. Daniel Panaccione in the Mycology/Molecular biology laboratory. Duties involved media preparation, transfer of fungal cultures, and transformation experiments with Acremonium coenophialum.

May 1992 - August 1993. University Conference Center, West Virginia University. Student desk supervisor, office assistant, cashier.

May 1988 - June 1992. McDonalds Restaurant. West Fairmont, West Virginia. Crewperson, cashier.

1988 - 1999. Poll clerk on counting boards for West Virginia primary, general, and special levy elections. 


\section{TEACHING EXPERIENCE}

Spring, 1998. PLSC 420/SPTP:TEACHING PRACTICUM. Teaching assistant for Environmental Microbiology 141 at WVU. Prepared for, presented, and oversaw labs.

October, 1996 - September, 1997. 4-H PROJECT LEADER OF ENVIRONMENTAL MANAGEMENT POWER, nine youth.

Fall, 1996. PLSC 420/SPTP:TEACHING PRACTICUM. Teaching assistant for Plant Pathology 201 at WVU. Designed, organized and presented labs; evaluated assignments. Presented two class lectures.

August 1 - 4, 1996. FIRST INTERNATIONAL CONFERENCE ON MYCORRHIZAE. University of California, Berkeley. Co-instructor of an international workshop on "Identification, Classification, and Manipulation of Arbuscular Fungi in Glomales", 54 participants from 23 countries.

Spring, 1995. AGED 492:SEM:COLLEGE TEACHING. Developed a syllabus and test, prepared lesson plans, presented a lecture and lab in class, and taught a lecture and lab for an environmental microbiology class (ENVM 201).

Summer, 1995 - Spring, 1999. TEACHER FOR JUNIOR CLASS AT HOULT UNITED METHODIST CHURCH.

Summer, 1990 - Spring, 1995. TEACHER FOR PRIMARY CLASS AT HOULT UNITED METHODIST CHURCH.

Fall, 1990 - Spring, 1991. PIANO INSTRUCTOR.

Summer, 1991. MATH AND ENGLISH TUTOR. Grade school level.

\section{ABSTRACTS}

Kinneer, K. L., K. M. Heldreth, and A. J. Sexstone. 1998. Size fractionation of bacterial functional diversity within soils. Third Annual College of Agriculture, Forestry, and Consumer Sciences Graduate Student Paper/Poster Session, Morgantown, WV.

Heldreth, K. and J. B. Morton. 1998. Functional dissection of a community of eleven arbuscular fungal species indigenous to a revegetated coal strip mine site. Second International Conference on Mycorrhizae, Uppsala, Sweden, July, 1998. (published)

Heldreth, K. M. and J. B. Morton. 1996. Threshold levels of mycorrhizal colonization are needed before sporulation is initiated in species of all genera in Glomales. First International Conference on Mycorrhizae, University of California, Berkeley, CA. (published)

Heldreth, K. M. and J. B. Morton. 1996. Threshold levels of mycorrhizal colonization are needed to initiate sporulation by fungal species in Glomales. First Annual College of 
Agriculture and Forestry/Agricultural and Forestry Experiment Station Graduate Student Paper/Poster Session, Morgantown, WV.

\section{ACTIVITIES}

June, 1995 - August, 1998. Organizational leader of Hoult-Sanford 4-H Club, Marion County, West Virginia.

October, 1995 - August, 1998.. Member of the county 4-H leaders' association; Winter, 1997. Chair of Winter Sports (organize county activity).

Fall, 1989 - present. Pianist, Catawba Charge choir; Fairmont, West Virginia.

Summer, 1987 - Spring, 1999. Co-pianist, Hoult United Methodist church; Fairmont, West Virginia.

January - December, 1996. Vice President of the Plant Pathology and Environmental Microbiology Graduate Student Association.

\section{ACADEMIC AFFILIATIONS}

Lifetime member of Golden Key National Honor Society

Allegheny Branch of the American Society of Microbiology

Alumnus of Mortar Board, Gamma Sigma Delta, Alpha Zeta, Phi Kappa Phi 
Appendix 1. Percent colonization, staining intensity, and dilutions of native AMF isolates used for effectiveness assays and for formulated community of selected native AMF.

\begin{tabular}{|c|c|c|c|c|c|}
\hline Isolate & Species & $\begin{array}{c}\% \text { colonization } \\
(\mathrm{MIP}) \pm \mathrm{SE}\end{array}$ & $\begin{array}{l}\text { Staining } \\
\text { intensity }\end{array}$ & $\begin{array}{c}\text { Dilution } \\
\text { (effectiveness) }\end{array}$ & $\begin{array}{c}\text { Dilution } \\
\text { (community) }\end{array}$ \\
\hline WV211B & G. occultum & $3.0 \pm 0.6$ & Light & $1 / 5$ & \\
\hline WV216A & G. luteum & $8.0 \pm 3.3$ & Light & $1 / 10$ & \\
\hline WV221 & G. diaphanum & $12.1 \pm 2.1$ & Mod & $1 / 10$ & \\
\hline WV212 & G. brasilianum & $18.0 \pm 1.7$ & Light & $1 / 15$ & $1 / 20$ \\
\hline WV216B & G. eburneum & $15.4 \pm 3.0$ & Light & $1 / 10$ & \\
\hline WV220 & G. claroideum & $26.8 \pm 6.4$ & Mod & $1 / 25$ & $1 / 25$ \\
\hline WV218 & Glomus sp. WV218 & $37.9 \pm 1.6$ & Mod-dark & $1 / 30$ & $1 / 35$ \\
\hline WV219A & G. clarum & $66.3 \pm 6.9$ & Dark & $1 / 40$ & $1 / 50$ \\
\hline WV230 & G. intraradices & $54.1 \pm 4.5$ & Dark & $1 / 30$ & $1 / 40$ \\
\hline WV214B & Glomus sp. WV214B & $26.2 \pm 3.5$ & Dark & $1 / 25$ & \\
\hline UT316 & G. etunicatum & $21.7 \pm 3.0$ & Mod & $1 / 20$ & \\
\hline BR147B & G. clarum & $63.9 \pm 5.5$ & Dark & $1 / 40$ & \\
\hline $\begin{array}{l}\text { BR147B } \\
+ \text { UT316 }\end{array}$ & $\begin{array}{l}\text { G. clarum } \\
+ \text { G. etunicatum }\end{array}$ & - & & $\begin{array}{c}\text { 1/80 G.clarum } \\
\text { 1/40 G.etunicatum }\end{array}$ & \\
\hline none & none & $0 \pm 0$ & & $1 / 20$ & \\
\hline
\end{tabular}


Appendix 2a. Occurrence of AMF species detected by sporulation in trap cultures of apple roots [Gingergold (Ggold), Golden Delicious (GD), and Fuji] from the Sept. 1995 sampling date. Two samples (A and B) were taken from each inoculum treatment $(1=$ a mixture of $G$. clarum and G. etunicatum previously used commercially; $2=$ a mixture of $G$. clarum and G. claroideum from the site; and, 3 = nonmycorrhizal inoculant).

\begin{tabular}{|c|c|c|c|c|c|c|c|c|c|c|c|c|c|c|c|c|c|c|}
\hline & 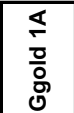 & 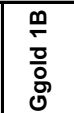 & $\begin{array}{l}\text { đ } \\
\text { 음 } \\
\text { ठ이 }\end{array}$ & 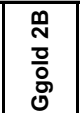 & 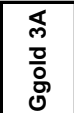 & 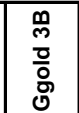 & $\begin{array}{l}\varangle \\
\text { O }\end{array}$ & $\frac{m}{0}$ & $\begin{array}{l}\text { N } \\
\text { Oे }\end{array}$ & 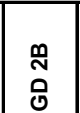 & $\begin{array}{l}\text { ऽ } \\
\text { O̊ }\end{array}$ & $\begin{array}{l}\text { m } \\
\text { Oᄋ }\end{array}$ & 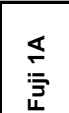 & 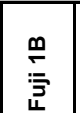 & 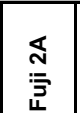 & 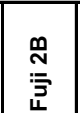 & 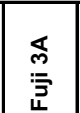 & 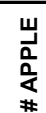 \\
\hline & & & & & & & & & & & & & & & & & & \\
\hline \multicolumn{19}{|l|}{ Species } \\
\hline G. intraradices & $X X X X$ & $X X X X$ & $X X X X$ & $x x x x$ & $X X X X$ & $x x x x$ & $x x x$ & $x x x$ & $x x x$ & $x x x x$ & $x x x$ & $x x x x$ & & & $x x x$ & & & 13 \\
\hline G. clarum & & $\mathrm{XXXX}$ & $X X X X$ & $\mathrm{XXXX}$ & & & & & & $\mathrm{XXXX}$ & & $\mathrm{XXXX}$ & $X X X X$ & $\mathrm{XXXX}$ & & & $\mathrm{XXXX}$ & 8 \\
\hline G. diaphanum & $X X X X$ & & $x x x x$ & $x x x$ & & & & & & $x X X X$ & & & & $\mathrm{XxXX}$ & & $x x x$ & $x x x x$ & 7 \\
\hline G. brasilianum & & $X X X X$ & & & & & & & & & & $\mathrm{XXXX}$ & $X X X X$ & $\mathrm{XXXX}$ & & & & 4 \\
\hline Glomus sp. WV218 & & & & & & $\mathrm{XXXX}$ & & & & & & $\mathrm{XXXX}$ & & & & & & 2 \\
\hline G. aggregatum & & & $X X X X$ & & & $x x x x$ & & & & & & & & & & & & 2 \\
\hline G. occultum & $X X X X$ & & & & & & & & & & & & & $\mathrm{XxXx}$ & & & & 2 \\
\hline G. etunicatum & & & & & & & & & & & & & & $\mathrm{XXXX}$ & & & & 1 \\
\hline G. luteum & & & & & & & & & & & & & & & & & & 0 \\
\hline G. eburneum & & & & & & & & & & & & & & & & & & 0 \\
\hline
\end{tabular}


Appendix 2b. Occurrence of AMF species detected by sporulation in trap cultures of apple [Gingergold (Ggold), Golden Delicious (GD), and Fuji] and grape [Aurore (Aur), Catawba (Cat), and Chardonnay (Char)] roots from the June 1996 sampling date. For apple, two samples (A and B) were taken from each inoculum treatment $(1=$ a mixture of $G$. clarum and $G$. etunicatum previously used commercially; $2=$ a mixture of $G$. clarum and $G$. claroideum from the site; and, $3=$ nonmycorrhizal inoculant) For grape, three samples $(1,2$, and 3 ) were taken from each inoculum treatment $(\mathrm{MYC}=$ a mixture of the four AMF isolates listed previously; and, $\mathrm{NON}=$ nonmycorrhizal inoculant). Bold font indicates dominant species sporulating in each trap culture.

\begin{tabular}{|c|c|c|c|c|c|c|c|c|c|c|c|c|c|c|c|c|c|c|c|}
\hline APPLE & & & & & & & & & & & & & & & & & & & \\
\hline & $\begin{array}{l}\frac{\square}{0} \\
\frac{0}{0} \\
\text { 인 }\end{array}$ & $\begin{array}{l}\stackrel{m}{-} \\
\text { 흥 } \\
\stackrel{5}{0}\end{array}$ & $\begin{array}{l}\text { đ } \\
\text { 응 } \\
\text { ס্ }\end{array}$ & 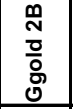 & $\begin{array}{l}\text { ్ } \\
\text { 흥 } \\
\text { 잉 }\end{array}$ & 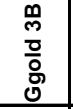 & $\begin{array}{l}\varangle \\
\vdots \\
0\end{array}$ & $\stackrel{m}{\stackrel{9}{0}}$ & $\begin{array}{l}\mathbb{N} \\
\text { 언 }\end{array}$ & $\begin{array}{l}\text { 品 } \\
\text { 怘 }\end{array}$ & $\begin{array}{l}\varangle \\
\text { ○ } \\
\text { 怘 }\end{array}$ & $\begin{array}{l}\boldsymbol{m} \\
\text { m } \\
\text { 号 }\end{array}$ & 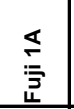 & $\begin{array}{l}\frac{\boldsymbol{m}}{2} \\
\frac{\bar{z}}{4}\end{array}$ & 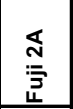 & $\begin{array}{l}\text { 吕 } \\
\text { 尔 } \\
\text { 山ا山 }\end{array}$ & 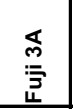 & 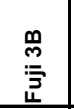 & 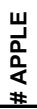 \\
\hline \# spores in $75 \mathrm{~cm}^{3}$ sample & 261 & 711 & 99 & 270 & 180 & 288 & 549 & 135 & 531 & 648 & 270 & 270 & 288 & 333 & 243 & 252 & 432 & 549 & \\
\hline \multicolumn{20}{|l|}{ Species } \\
\hline G. intraradices & $\mathbf{X X X X}$ & $\mathbf{X X X X}$ & $\mathbf{X X X X}$ & $\mathbf{X X X X}$ & $\mathbf{X X X X}$ & $\mathbf{X X X X}$ & $\mathbf{X X X X}$ & $\mathbf{X X X X}$ & $\mathbf{X X X X}$ & $\mathrm{XXXX}$ & $\mathbf{X X X X}$ & $\mathbf{X X X X}$ & $\mathrm{XXXX}$ & $\mathbf{X X X X}$ & & $\mathbf{X X X X}$ & $\mathbf{X X X X}$ & $\mathrm{XXXX}$ & 17 \\
\hline G. clarum & & & & $\mathrm{XXXX}$ & & & & & & $\mathrm{XXXX}$ & & $\mathrm{XXXX}$ & & & $\mathbf{X X X X}$ & & & $\mathbf{x x X X}$ & 5 \\
\hline G. diaphanum & $\mathrm{XXXX}$ & & $\mathrm{XXXX}$ & & & $\mathrm{XXXX}$ & & & & & & $\mathrm{XXXX}$ & & & & $\mathrm{XXXX}$ & $\mathrm{XXXX}$ & $\mathrm{XXXX}$ & 7 \\
\hline G. brasilianum & & $\mathrm{XXXX}$ & & & & & & & & $\mathbf{X X X X}$ & & $\mathrm{XXXX}$ & $\mathbf{X X X X}$ & $\mathrm{XXXX}$ & & & & & 5 \\
\hline Glomus sp. WV218 & & $\mathrm{XXXX}$ & & $\mathrm{XXXX}$ & & & & & & & & $\mathrm{XXXX}$ & & $\mathrm{XXXX}$ & & & $\mathrm{XXXX}$ & & 5 \\
\hline G. aggregatum & & & & $\mathrm{XXXX}$ & $\mathrm{XXXX}$ & & & & & & $\mathrm{XXXX}$ & & & & & & & & 3 \\
\hline G. occultum & & & & & & & $\mathrm{XXXX}$ & & & & & & & & & & & & 1 \\
\hline G. etunicatum & & & & & & & & & & & & & & & & & & & 0 \\
\hline G. luteum & & $\mathrm{XXXX}$ & & & & & & & & & & & & & & & & & 1 \\
\hline G. eburneum & & & & & & & & & & & $\mathrm{XXXX}$ & & & & & & & & 1 \\
\hline
\end{tabular}

\begin{tabular}{|c|c|c|c|c|c|c|c|c|c|c|c|c|c|c|c|c|c|c|}
\hline GRAPE & & & & & & & & & & & & & & & & & & \\
\hline & $\begin{array}{l}\mathbf{2} \\
\mathbf{Z} \\
\mathbf{Z} \\
\vdots \\
\mathbf{Z}\end{array}$ & $\begin{array}{l}\text { m } \\
\mathbf{2} \\
\mathbf{0} \\
\mathbf{z} \\
\bar{z}\end{array}$ & 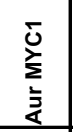 & 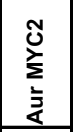 & $\underset{\sum}{\substack{Z \\
⿱ 亠 䒑}}$ & 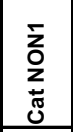 & $\begin{array}{l}\text { N } \\
\mathbf{z} \\
\mathbf{z} \\
\text { 范 }\end{array}$ & $\begin{array}{l}\text { m } \\
\mathbf{z} \\
\mathbf{z} \\
\mathbf{J} \\
0\end{array}$ & 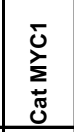 & 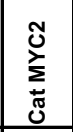 & 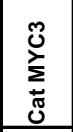 & $\begin{array}{l}\bar{z} \\
\mathbf{z} \\
\mathbf{z} \\
\frac{1}{\pi} \\
\frac{\pi}{0}\end{array}$ & $\begin{array}{l}\text { N } \\
\mathbf{0} \\
\mathbf{z} \\
\vdots \\
\frac{\pi}{0}\end{array}$ & $\begin{array}{l}\text { m } \\
\text { O } \\
\mathbf{z} \\
\frac{1}{\pi} \\
\frac{\pi}{0}\end{array}$ & 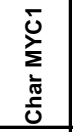 & 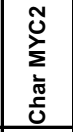 & $\begin{array}{l}\stackrel{0}{0} \\
\sum \\
\frac{\pi}{\pi} \\
\frac{\pi}{0}\end{array}$ & 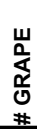 \\
\hline \# spores in $75 \mathrm{~cm}^{3}$ sample & 1161 & 153 & 207 & 405 & 189 & 324 & 342 & 405 & 198 & 189 & 234 & 441 & 369 & 90 & 261 & 396 & 657 & \\
\hline \multicolumn{19}{|l|}{ Species } \\
\hline G. intraradices & $\mathrm{XXXX}$ & XXXX & $\mathbf{X X X X}$ & $\mathrm{XXXX}$ & $\mathrm{XXXX}$ & XXXX & XXXX & XXXX & XXXX & XXXX & $\mathrm{XXXX}$ & XXXX & $\mathrm{XXXX}$ & $\mathbf{X X X X}$ & $\mathbf{X X X X}$ & XXXX & $\mathrm{XXXX}$ & 17 \\
\hline G. clarum & & & & & & & & & & & & & & & & & & 0 \\
\hline G. diaphanum & & & & & & $\mathrm{XXXX}$ & & & & & $\mathrm{XXXX}$ & & & & & & $\mathrm{XXXX}$ & 3 \\
\hline G. brasilianum & & & & & & & & & & & & & & & & & & 0 \\
\hline Glomus sp. WV218 & & & & & & & & & & & & & & & & $X X X X$ & & 1 \\
\hline G. aggregatum & & $\mathrm{XXXX}$ & & & & & & & & & & & & & & & & 1 \\
\hline G. occultum & & & & & & & & & & & & & & & & & & 0 \\
\hline G. etunicatum & & & & & & & & & & & & & & & & & & 0 \\
\hline G. luteum & & & & & & & & & & & & & & & & & & 0 \\
\hline G. eburneum & & & & & & & & & & & & & & & & & & 0 \\
\hline
\end{tabular}


Appendix 2c. Occurrence of AMF species detected by sporulation in trap cultures of apple [Gingergold (Ggold), Golden Delicious (GD), and Fuji] and grape [Aurore (Aur), Catawba (Cat), and Chardonnay (Char)] roots from the Oct. 1996 sampling date. For apple, two samples (A and B) were taken from each inoculum treatment $(1=$ a mixture of $G$. clarum and G. etunicatum previously used commercially; $2=$ a mixture of $G$. clarum and $G$. claroideum from the site; and, $3=$ nonmycorrhizal inoculant) For grape, three samples $(1,2$, and 3$)$ were taken from each inoculum treatment $(\mathrm{MYC}=$ a mixture of the four AMF isolates listed previously; and, $\mathrm{NON}=$ nonmycorrhizal inoculant). Bold font indicates dominant species sporulating in each trap culture.

\begin{tabular}{|c|c|c|c|c|c|c|c|c|c|c|c|c|c|c|c|c|c|c|c|}
\hline APPLE & & & & & & & & & & & & & & & & & & & \\
\hline & $\begin{array}{l}\frac{\pi}{5} \\
\text { 흥 } \\
\text { 엉 }\end{array}$ & $\begin{array}{l}\text { m } \\
\text { 흥 } \\
\text { o }\end{array}$ & $\begin{array}{l}\text { ঐ } \\
\text { 흥 } \\
\text { 앙 }\end{array}$ & $\begin{array}{l}\stackrel{m}{N} \\
\text { o } \\
\text { 임 }\end{array}$ & $\begin{array}{l}\text { 吕 } \\
\text { 응 } \\
\text { o }\end{array}$ & $\begin{array}{l}m \\
\text { m } \\
\text { o } \\
\text { 임 }\end{array}$ & $\begin{array}{l}\varangle \\
\text { 웅 }\end{array}$ & $\begin{array}{l}\stackrel{m}{\sigma} \\
\stackrel{9}{0}\end{array}$ & $\begin{array}{l}\text { đ } \\
\text { 号 }\end{array}$ & $\begin{array}{l}\stackrel{\mathscr{N}}{\text { N }} \\
\text { 号 }\end{array}$ & 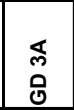 & 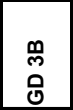 & $\begin{array}{l}\mathbb{8} \\
: \frac{5}{3} \\
\end{array}$ & 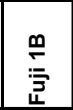 & 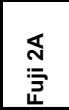 & 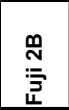 & 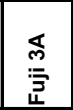 & 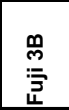 & 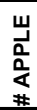 \\
\hline \# spores in $75 \mathrm{~cm}^{3}$ sample & 864 & 2907 & 954 & 1449 & 405 & 4347 & 882 & 531 & 837 & 1134 & 1197 & 1134 & 801 & 684 & 1296 & 1656 & 756 & 585 & \\
\hline \multicolumn{20}{|l|}{ Species } \\
\hline G. intraradices & $x \times x X$ & $X X X X$ & $x x x x$ & $\mathrm{XXXX}$ & XXXX & $\mathrm{XXXX}$ & $\mathrm{XXXX}$ & $x x x x$ & $\mathrm{XXXX}$ & $\mathrm{XXXX}$ & $x x x x$ & $X X X X$ & $x x x x$ & $x x x x$ & $X X X X$ & $x \times x x$ & $\mathrm{XXXX}$ & $x x x x$ & 18 \\
\hline G. clarum & & & & & & & & & & & & $X X X X$ & $X X X X$ & & $X X X X$ & & & & 3 \\
\hline G. diaphanum & & & & $X X X X$ & $X X X X$ & $X X X X$ & & & & & & $\mathrm{XXXX}$ & & & & & & & 4 \\
\hline G. brasilianum & & $X X X X$ & $X X X X$ & & & & & & & $X X X X$ & & & $X X X X$ & $X X X X$ & & & & $X X X X$ & 6 \\
\hline Glomus sp. WV218 & & $\mathrm{XXXX}$ & & & & & & $\mathrm{XXXX}$ & & & & $\mathrm{XXXX}$ & & & & & & & 3 \\
\hline G. aggregatum & & & & & & & & & & & & & & & & $\mathrm{XXXX}$ & & & 1 \\
\hline G. occultum & & & & & & & & & & $\mathrm{XXXX}$ & & & & & & & & & 1 \\
\hline G. etunicatum & & & & & & & & & & & & & & & & & & & 0 \\
\hline G. luteum & & & & & & & & & & & & & & & & & & & 0 \\
\hline G. eburneum & & & & & & & & & & & & & & & & & & & 0 \\
\hline
\end{tabular}

\begin{tabular}{|c|c|c|c|c|c|c|c|c|c|c|c|c|c|c|c|c|c|}
\hline GRAPE & & & & & & & & & & & & & & & & & \\
\hline & $\begin{array}{l}\bar{z} \\
\text { Ò } \\
\mathbf{z} \\
\bar{z}\end{array}$ & 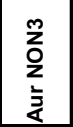 & 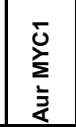 & 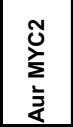 & 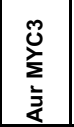 & \begin{tabular}{l}
$\bar{z}$ \\
$\mathbf{z}$ \\
$\mathbf{z}$ \\
\multirow{0}{0}{}
\end{tabular} & $\begin{array}{l}\mathbf{N} \\
\mathbf{Z} \\
\mathbf{Z} \\
\mathbb{N} \\
0\end{array}$ & \begin{tabular}{l} 
m \\
$\mathbf{2}$ \\
$\mathbf{2}$ \\
\multirow{0}{*}{}
\end{tabular} & 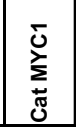 & 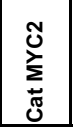 & 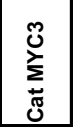 & $\begin{array}{l}\mathbf{z} \\
\mathbf{0} \\
\mathbf{z} \\
\frac{1}{\pi} \\
\frac{1}{0}\end{array}$ & $\begin{array}{l}\text { Z } \\
\text { O } \\
\mathbf{2} \\
\frac{1}{\pi} \\
\frac{1}{0}\end{array}$ & $\begin{array}{l}\text { Z } \\
\text { O } \\
\mathbf{2} \\
\frac{1}{\pi} \\
\frac{1}{0}\end{array}$ & 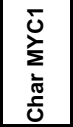 & 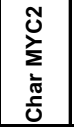 & 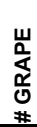 \\
\hline \# spores in $75 \mathrm{~cm}^{3}$ sample & 171 & 369 & 909 & 387 & 333 & 333 & 783 & 927 & 396 & 1485 & 477 & 2592 & 1359 & 2250 & 486 & 1503 & \\
\hline \multicolumn{18}{|l|}{ Species } \\
\hline G. intraradices & $\mathrm{XXXX}$ & $\mathrm{XXXX}$ & $x x x x$ & $\mathrm{XXXX}$ & XXXX & XXXX & $X X X X$ & $x x x x$ & $x x x x$ & XXXX & $\mathrm{XXXX}$ & XXXX & $\mathrm{XXXX}$ & $\mathrm{XXXX}$ & $\mathrm{XXXX}$ & $\mathbf{X X X X}$ & 16 \\
\hline G. clarum & & & & & & & & & & & & & & & & & 0 \\
\hline G. diaphanum & & & & & & & & & & & $\mathrm{XXXX}$ & & & & & & 1 \\
\hline G. brasilianum & & & & & & & $X X X X$ & $\mathrm{XXXX}$ & & & & & $\mathrm{XXXX}$ & & & & 3 \\
\hline Glomus sp. WV218 & & $\mathrm{XXXX}$ & & $\mathrm{XXXX}$ & & & & & & & & & & & & & 2 \\
\hline G. aggregatum & & & & & & & & & & & & & & & & & 0 \\
\hline G. occultum & & & & & & & & & & & & & & & & & 0 \\
\hline G. etunicatum & & & & & & & & & & & & & & & & & 0 \\
\hline G. luteum & & & & & & & & & & & & & & & & & 0 \\
\hline G. eburneum & & & & & & & & & & & & & & & & & 0 \\
\hline
\end{tabular}


Appendix 3a. Number of spores per $50 \mathrm{~cm}^{3}$ soil and percent colonization of A. morrowiae BR983A at 21-day intervals after the first sampling date (4 weeks after plant emergence). ND $=$ not determined.

\begin{tabular}{|c|c|c|c|c|c|c|c|c|}
\hline & \multicolumn{2}{|c|}{ 1st sampling } & \multicolumn{2}{c|}{ 2nd sampling } & \multicolumn{2}{c|}{ 3rd sampling } & \multicolumn{2}{|c|}{ 4th sampling } \\
\hline & \# spores & $\%$ col. & \# spores & $\%$ col. & \# spores & $\%$ col. & \# spores & col. \\
\hline Am 0 P & & & & & & & & \\
$\# 1$ & ND & ND & ND & ND & ND & ND & ND & ND \\
$\# 2$ & 209 & $14.0 \%$ & 1315 & $17.0 \%$ & 5976 & $23.0 \%$ & 9095 & $21.0 \%$ \\
$\# 3$ & 47 & $11.0 \%$ & 661 & $13.0 \%$ & 3842 & $27.0 \%$ & 9981 & $24.0 \%$ \\
$\# 4$ & 261 & $16.0 \%$ & 925 & $26.0 \%$ & 7716 & $23.0 \%$ & 8208 & $22.0 \%$ \\
\hline avg. & 172 & $13.7 \%$ & 967 & $18.7 \%$ & 5845 & $24.3 \%$ & 9095 & $22.3 \%$ \\
\hline & & & & & & & & \\
Am 150 P & & & & & & & & \\
$\# 1$ & 0 & $0.0 \%$ & ND & $2.0 \%$ & 0 & $0.2 \%$ & 0 & $0.0 \%$ \\
$\# 2$ & 1 & $0.4 \%$ & 0 & $0.0 \%$ & 2 & $0.0 \%$ & 1 & $7.0 \%$ \\
$\# 3$ & 4 & $2.0 \%$ & 6 & $3.0 \%$ & 7 & $2.0 \%$ & 17 & $4.0 \%$ \\
$\# 4$ & 0 & $2.0 \%$ & 4 & $2.0 \%$ & 3 & $0.0 \%$ & 7 & $4.0 \%$ \\
\hline avg. & 1 & $1.1 \%$ & 3 & $1.8 \%$ & 3 & $0.6 \%$ & 6 & $3.8 \%$ \\
\hline & & & & & & & & \\
Am 450 P & & & & & & & & \\
$\# 1$ & 0 & $0.0 \%$ & 0 & $0.0 \%$ & 0 & $0.0 \%$ & 0 & $0.0 \%$ \\
$\# 2$ & 1 & $1.0 \%$ & 0 & $0.0 \%$ & 0 & $0.3 \%$ & 0 & $0.0 \%$ \\
$\# 3$ & 3 & $0.0 \%$ & 0 & $0.0 \%$ & 1 & $0.0 \%$ & 2 & $0.0 \%$ \\
$\# 4$ & 0 & $0.0 \%$ & 1 & $0.0 \%$ & 3 & $0.0 \%$ & 11 & $0.2 \%$ \\
\hline avg. & 1 & $0.3 \%$ & 0 & $0.0 \%$ & 1 & $0.1 \%$ & 3 & $0.1 \%$ \\
\hline
\end{tabular}


Appendix 3b. Number of spores per $50 \mathrm{~cm}^{3}$ soil and percent colonization of G. etunicatum WV977 at 21-day intervals after the first sampling date (4 weeks after plant emergence). ND = not determined.

\begin{tabular}{|c|c|c|c|c|c|c|c|c|}
\hline & \multicolumn{2}{|c|}{ 1st sampling } & \multicolumn{2}{c|}{ 2nd sampling } & \multicolumn{2}{c|}{ 3rd sampling } & \multicolumn{2}{c|}{ 4th sampling } \\
\hline & \# spores & $\%$ col. & \# spores & $\%$ col. & \# spores & $\%$ col. & \# spores & $\%$ col. \\
\hline Ge 0 P & & & & & & & & \\
$\# 1$ & 467 & $14.0 \%$ & 1223 & $17.0 \%$ & 2988 & $20.0 \%$ & 7191 & $26.0 \%$ \\
$\# 2$ & 499 & $13.0 \%$ & 811 & $22.0 \%$ & 1839 & $19.0 \%$ & 5155 & $24.0 \%$ \\
$\# 3$ & 223 & $13.0 \%$ & 442 & $23.0 \%$ & 3382 & $16.0 \%$ & 4728 & $21.0 \%$ \\
$\# 4$ & 509 & $26.0 \%$ & 516 & $19.0 \%$ & 2922 & $26.0 \%$ & 8438 & $23.0 \%$ \\
\hline avg. & 425 & $16.5 \%$ & 748 & $20.3 \%$ & 2783 & $20.3 \%$ & 6378 & $23.5 \%$ \\
\hline & & & & & & & & \\
Ge 150 P & & & & & & & & \\
$\# 1$ & 0 & $2.0 \%$ & 6 & $2.0 \%$ & 64 & $3.0 \%$ & 188 & $3.0 \%$ \\
$\# 2$ & 137 & $3.0 \%$ & 56 & $3.0 \%$ & 105 & $7.0 \%$ & 250 & $3.0 \%$ \\
$\# 3$ & 17 & $3.0 \%$ & 74 & $4.0 \%$ & 167 & $3.0 \%$ & 289 & $4.0 \%$ \\
$\# 4$ & 13 & $3.0 \%$ & 21 & $1.0 \%$ & 48 & $4.0 \%$ & 180 & $6.0 \%$ \\
\hline avg. & 42 & $2.8 \%$ & 39 & $2.5 \%$ & 96 & $4.3 \%$ & 227 & $4.0 \%$ \\
\hline & & & & & & & & \\
Ge 450 P & & & & & & & & \\
$\# 1$ & 37 & $4.0 \%$ & 31 & $7.0 \%$ & 40 & $2.0 \%$ & 69 & $1.0 \%$ \\
$\# 2$ & 16 & $4.0 \%$ & 17 & $0.0 \%$ & 32 & $3.0 \%$ & 335 & $1.0 \%$ \\
$\# 3$ & $\mathrm{ND}$ & $\mathrm{ND}$ & $\mathrm{ND}$ & $\mathrm{ND}$ & $\mathrm{ND}$ & $\mathrm{ND}$ & $\mathrm{ND}$ & $\mathrm{ND}$ \\
\#4 & 33 & $1.0 \%$ & 28 & $1.0 \%$ & 32 & $1.0 \%$ & 41 & $0.4 \%$ \\
\hline avg. & 29 & $3.0 \%$ & 25 & $2.7 \%$ & 35 & $2.0 \%$ & 148 & $0.8 \%$ \\
\hline
\end{tabular}


Appendix 3c. Number of spores per $50 \mathrm{~cm}^{3}$ soil and percent colonization of $G$. intraradices UT187 at 21-day intervals after the first sampling date (4 weeks after plant emergence).

\begin{tabular}{|c|c|c|c|c|c|c|c|c|}
\hline & \multicolumn{2}{|c|}{ 1st sampling } & \multicolumn{2}{c|}{ 2nd sampling } & \multicolumn{2}{c|}{ 3rd sampling } & \multicolumn{2}{c|}{ 4th sampling } \\
\hline & \# spores & $\%$ col. & \# spores & $\%$ col. & \# spores & $\%$ col. & \# spores & $\%$ col. \\
\hline Gi 0 P & & & & & & & & \\
\#1 & 160 & $20.0 \%$ & 643 & $40.0 \%$ & 5844 & $62.0 \%$ & 3907 & $58.0 \%$ \\
$\# 2$ & 454 & $39.0 \%$ & 518 & $34.0 \%$ & 2955 & $47.0 \%$ & 4630 & $55.0 \%$ \\
$\# 3$ & 254 & $23.0 \%$ & 488 & $33.0 \%$ & 3382 & $60.0 \%$ & 3349 & $60.0 \%$ \\
\#4 & 230 & $38.0 \%$ & 556 & $49.0 \%$ & 2036 & $46.0 \%$ & 3546 & $57.0 \%$ \\
\hline avg. & 275 & $30.0 \%$ & 551 & $39.0 \%$ & 3554 & $53.8 \%$ & 3858 & $57.5 \%$ \\
\hline & & & & & & & & \\
Gi 150 P & & & & & & & & \\
$\# 1$ & 0 & $8.0 \%$ & 5 & $2.0 \%$ & 4 & $8.0 \%$ & 3 & $4.0 \%$ \\
$\# 2$ & 1 & $10.0 \%$ & 2 & $4.0 \%$ & 3 & $2.0 \%$ & 14 & $13.0 \%$ \\
$\# 3$ & 0 & $8.0 \%$ & 6 & $4.0 \%$ & 10 & $3.0 \%$ & 12 & $9.0 \%$ \\
\#4 & 11 & $13.0 \%$ & 12 & $5.0 \%$ & 9 & $5.0 \%$ & 7 & $8.0 \%$ \\
\hline avg. & 3 & $9.8 \%$ & 6 & $3.8 \%$ & 7 & $4.5 \%$ & 9 & $8.5 \%$ \\
\hline & & & & & & & & \\
Gi 450 P & & & & & & & & \\
\#1 & 0 & $1.0 \%$ & 0 & $1.0 \%$ & 0 & $0.0 \%$ & 0 & $0.0 \%$ \\
$\# 2$ & 0 & $2.0 \%$ & 0 & $1.0 \%$ & 0 & $0.0 \%$ & 0 & $0.0 \%$ \\
\#3 & 0 & $3.0 \%$ & 0 & $1.0 \%$ & 0 & $0.4 \%$ & 0 & $0.2 \%$ \\
\#4 & 0 & $3.0 \%$ & 0 & $0.3 \%$ & 0 & $0.0 \%$ & 0 & $0.0 \%$ \\
\hline avg. & 0 & $2.3 \%$ & 0 & $0.8 \%$ & 0 & $0.1 \%$ & 0 & $0.1 \%$ \\
\hline
\end{tabular}


Appendix 3d. Number of spores per $50 \mathrm{~cm}^{3}$ soil and percent colonization of Gi. gigantea MN922A at 21-day intervals after the first sampling date (4 weeks after plant emergence). Note: one additional sampling time was included a week following the 2 nd regular sampling. $\mathrm{ND}=$ not determined.

\begin{tabular}{|c|c|c|c|c|c|c|c|c|c|c|}
\hline & \multicolumn{2}{|c|}{ 1st sampling } & \multicolumn{2}{c|}{ 2nd sampling } & \multicolumn{2}{c|}{ one week later } & \multicolumn{2}{c|}{ 3rd sampling } & \multicolumn{2}{c|}{ 4th sampling } \\
\hline & \# spores & $\%$ col. & \# spores & $\%$ col. & \# spores & $\%$ col. & \# spores & $\%$ col. & \# spores & $\%$ col. \\
\hline Gig 0 P & & & & & & & & & & \\
$\# 1$ & 7 & $34.0 \%$ & 276 & $39.0 \%$ & 304 & $39.0 \%$ & 507 & $70.0 \%$ & 1416 & $60.0 \%$ \\
$\# 2$ & 0 & $32.0 \%$ & 123 & $32.0 \%$ & 340 & $43.0 \%$ & 565 & $69.0 \%$ & 1154 & $57.0 \%$ \\
$\# 3$ & 4 & $33.0 \%$ & 165 & $39.0 \%$ & 349 & $48.0 \%$ & 690 & $54.0 \%$ & 1036 & $58.0 \%$ \\
$\# 4$ & 3 & $18.0 \%$ & 157 & $34.0 \%$ & 225 & $34.0 \%$ & 851 & $59.0 \%$ & 1249 & $70.0 \%$ \\
\hline avg. & 4 & $29.3 \%$ & 180 & $36.0 \%$ & 305 & $41.0 \%$ & 653 & $63.0 \%$ & 1214 & $61.3 \%$ \\
\hline & & & & & & & & & & \\
Gig 150 P & & & & & & & & & & \\
$\# 1$ & 0 & $15.0 \%$ & ND & $10.0 \%$ & 51 & $19.0 \%$ & 146 & $13.0 \%$ & 214 & $13.0 \%$ \\
$\# 2$ & 0 & $9.0 \%$ & ND & $17.0 \%$ & 28 & $17.0 \%$ & 97 & $14.0 \%$ & 119 & $23.0 \%$ \\
$\# 3$ & 0 & $11.0 \%$ & ND & $8.0 \%$ & 14 & $4.0 \%$ & 68 & $13.0 \%$ & 182 & $20.0 \%$ \\
$\# 4$ & 0 & $5.0 \%$ & 22 & $7.0 \%$ & 31 & $10.0 \%$ & 79 & $10.0 \%$ & 149 & $20.0 \%$ \\
\hline avg. & 0 & $10.0 \%$ & 22 & $10.5 \%$ & 31 & $12.5 \%$ & 98 & $12.5 \%$ & 166 & $19.0 \%$ \\
\hline & & & & & & & & & & \\
Gig 450 P & & & & & & & & & & \\
$\# 1$ & 0 & $7.0 \%$ & ND & $7.0 \%$ & 1 & $9.0 \%$ & 10 & $3.0 \%$ & 9 & $0.3 \%$ \\
$\# 2$ & 0 & $11.0 \%$ & ND & $7.0 \%$ & 0 & $7.0 \%$ & 6 & $7.0 \%$ & 23 & $6.0 \%$ \\
$\# 3$ & 0 & $10.0 \%$ & ND & $5.0 \%$ & 3 & $13.0 \%$ & 29 & $5.0 \%$ & 28 & $5.0 \%$ \\
$\# 4$ & 0 & $6.0 \%$ & ND & $8.0 \%$ & 0 & $6.0 \%$ & 8 & $4.0 \%$ & 31 & $4.0 \%$ \\
\hline avg. & 0 & $8.5 \%$ & & $6.8 \%$ & 1 & $8.8 \%$ & 13 & $4.8 \%$ & 23 & $3.8 \%$ \\
\hline
\end{tabular}


Appendix 3e. Number of spores per $50 \mathrm{~cm}^{3}$ soil and percent colonization of $S$. heterogama WV858B at 21-day intervals after the first sampling date (4 weeks after plant emergence). ND = not determined.

\begin{tabular}{|c|c|c|c|c|c|c|c|c|}
\hline & \multicolumn{2}{|c|}{ 1st sampling } & \multicolumn{2}{c|}{ 2nd sampling } & \multicolumn{2}{c|}{ 3rd sampling } & \multicolumn{2}{c|}{ 4th sampling } \\
\hline & \# spores & $\%$ col. & \# spores & $\%$ col. & \# spores & $\%$ col. & \# spores & $\%$ col. \\
\hline Sh 0 P & & & & & & & & \\
$\# 1$ & 0 & $16.0 \%$ & 25 & $21.0 \%$ & 405 & $26.0 \%$ & 2397 & $44.0 \%$ \\
$\# 2$ & 3 & $35.0 \%$ & 55 & $23.0 \%$ & 432 & $34.0 \%$ & 2758 & $49.0 \%$ \\
$\# 3$ & 1 & $21.0 \%$ & 71 & $32.0 \%$ & 458 & $31.0 \%$ & 1773 & $41.0 \%$ \\
$\# 4$ & 3 & $30.0 \%$ & 8 & $23.0 \%$ & 359 & $32.0 \%$ & 1773 & $41.0 \%$ \\
\hline avg. & 2 & $25.5 \%$ & 40 & $24.8 \%$ & 414 & $30.8 \%$ & 2175 & $43.8 \%$ \\
\hline & & & & & & & & \\
Sh 150 P & & & & & & & & \\
$\# 1$ & 0 & $2.0 \%$ & 0 & $3.0 \%$ & 3 & $9.0 \%$ & 48 & $9.0 \%$ \\
$\# 2$ & 0 & $0.4 \%$ & 0 & $1.0 \%$ & 2 & $4.0 \%$ & 13 & $6.0 \%$ \\
$\# 3$ & 0 & $3.0 \%$ & 0 & $7.0 \%$ & 57 & $21.0 \%$ & 78 & $10.0 \%$ \\
$\# 4$ & 0 & $0.0 \%$ & 0 & $6.0 \%$ & 76 & $4.0 \%$ & 89 & $10.0 \%$ \\
\hline avg. & 0 & $1.4 \%$ & 0 & $4.3 \%$ & 35 & $9.5 \%$ & 57 & $8.8 \%$ \\
\hline & & & & & & & & \\
Sh 450 P & & & & & & & & \\
$\# 1$ & ND & ND & ND & ND & ND & ND & ND & ND \\
\#2 & 0 & $2.0 \%$ & 0 & $6.0 \%$ & 0 & $2.0 \%$ & 0 & $2.0 \%$ \\
$\# 3$ & 0 & $1.0 \%$ & 0 & $1.0 \%$ & 0 & $2.0 \%$ & 0 & $0.4 \%$ \\
\#4 & 0 & $2.0 \%$ & 0 & $1.0 \%$ & 0 & $0.0 \%$ & 0 & $0.4 \%$ \\
\hline avg. & 0 & $1.7 \%$ & 0 & $2.7 \%$ & 0 & $1.3 \%$ & 0 & $0.9 \%$ \\
\hline
\end{tabular}

